\title{
Backward Trajectory and Multifractal Analysis of Air Pollution in Zhengzhou Region of China
}

\author{
Qizhen Wang $\mathbb{D}^{1}{ }^{1}$ Tong Zhao, ${ }^{1}$ Rong Wang, ${ }^{1}$ and Ling Zhang ${ }^{1,2}$ \\ ${ }^{1}$ Business School, Nanjing Xiaozhuang University, Nanjing, China \\ ${ }^{2}$ School of Accountancy, TongLing University, Tongling, China \\ Correspondence should be addressed to Qizhen Wang; wqz@njxzc.edu.cn
}

Received 14 September 2021; Revised 8 December 2021; Accepted 17 December 2021; Published 13 January 2022

Academic Editor: Yingkun Hou

Copyright ( 2022 Qizhen Wang et al. This is an open access article distributed under the Creative Commons Attribution License, which permits unrestricted use, distribution, and reproduction in any medium, provided the original work is properly cited.

With the continuous promotion of industrialization and urbanization, China's environmental pollution is becoming increasingly serious, which has caused considerable damage to the natural balance. Air pollution seriously harms people's physical and mental health, the ecological environment, and the social sustainable development of society. In this study, the backward trajectory model and multifractal methods were adopted to analyze air pollution in Zhengzhou. The backward trajectory analysis showed that most clusters of air pollution were from southern Hebei, eastern Shandong, and mid-western Henan, which were then transported to Zhengzhou. For the PSCF and CWT analyses, we selected four representative cities to explore how close the air pollution of Zhengzhou is to other areas on the basis of air polluted concentration. The results of several multifractal methods indicated that multifractality existed in the AQI time series of Zhengzhou and cross-correlations between Zhengzhou and each of the four cities. The widths of multifractal spectra showed that the air pollution in Zhengzhou was closest to that in Jinan, followed by Shijiazhuang, Zibo, and Luoyang. The CDFA analysis showed that carbon monoxide (CO), nitrogen dioxide $\left(\mathrm{NO}_{2}\right)$, and inhalable particulate matter $\left(\mathrm{PM}_{10}\right)$ had important influences on air pollution in Zhengzhou. These findings offer a useful reference for air pollution sources and their potential contributions in Zhengzhou, which can support policy makers in environmental governance and in achieving sustainable urban development.

\section{Introduction}

Aerosols are colloids of fine solid particles or liquid droplets suspended in the atmosphere that affect climate, weather, and air quality through a variety of mechanisms. Aerosols can significantly affect climate through the effects of aerosolradiation interactions (ARIs), aerosol-cloud interactions (ACIs), or both. Strong interaction between aerosols and meteorological variables occur in the planetary boundary layer (PBL). The PBL involves a number of chemical, physical, and dynamic processes that are closely related to the accumulation of aerosol pollution, which has a negative impact on the climate and environment and poses a threat to human health [1-3].For example, exposures to aeroallergens may cause allergy symptoms, especially for sensitized patients. Many people may be allergic to pollen, leading to seasonal rhinitis or skin diseases. Moreover, the transport of the pollen from distant sources may result in allergy symptoms in sensitized patients after the flowering periods [4].

The main factors that cause air pollution are natural sources and human activities. Natural sources mainly include plant pollen, soil dust, forest fire, and volcanic eruption, whereas human activities mainly include burning fuel, industrial emissions, and vehicle emissions. Dust storms (DSs) are natural phenomena that are prevalent in the areas with loose sands, especially in the Middle East, the Southwestern United States, Northern China, and the Saharan Desert. DSs cause not only environmental and human health problems but also decrease in visibility, which limits various activities and increases traffic accidents [5].

As for human activities, Bari and Kindzierski [6] investigated air quality characteristics and potential sources affecting $\mathrm{PM}_{2.5}$ concentrations in the community of Hinton, 
Alberta, Canada. They found that local industry emissions such as Hinton pulp and wood products had moderate influences from the southwest direction. Shipping emissions were regarded as an important factor associated with particulate matter, and the potential of offshore activities and shipping emissions may influence the air quality in urban areas located more than $1000 \mathrm{~km}$ away from the cities [7]. Anthropogenic activities combined with vehicular emissions influence the mixing ratios of $\mathrm{CO}$ and $\mathrm{NO}_{2}$ due to office/ working hours and the shallowing and widening of boundary layer. $\mathrm{NO}_{2}$ and $\mathrm{CO}$ pollutants from urban traffic help increase $\mathrm{O}_{3}$, which results in higher $\mathrm{O}_{3}$ mixing ratios during the rush hours and daylight period. The planetary boundary layer (PBL) is crucial in determining $\mathrm{O}_{3}$ mixing ratios. The PBL is shallow and wide during the winter and post-monsoon season, which leads to the stagnation of gaseous pollutants due to low atmospheric temperature. During summer, PBL is deep, with frequent mixing of the pollutants causing dilution of the pollutants due to higher solar radiation. These mixing ratios indicate that the highest mean mixing ratios of $\mathrm{O}_{3}$ during the day are greater than at night [8]. Outdoor barbecues may have a potential impact on the air quality in a city. Atmospheric aerosols produced by the burning of mixed hardwoods and agricultural wastes influence environmental conditions in another region [9]. With the continuous development of industrialization and urbanization in China, the environmental deterioration caused by aerosol pollution has been increasingly significant, seriously harming human health and the ecological environment. The huge economic advances achieved at the expense of the environment have undoubtedly increased the pressure on the environment, harmed the physical and mental health of people, and incurred large costs in terms of sustainable economic development [10].

In the study of air pollution and human health, scholars have found that air pollution damages the human immune system and respiratory systems [11-13]. For example, ozone is a poisonous gas and, if inhaled, can cause oxidative damages and inflammation, leading to neurodegenerative pathologies, especially Alzheimer's disease [12]. Exposure to $\mathrm{NO}_{2}$ is also associated with leukocyte telomere length, a marker of molecular ageing, which leads to health problems [14]. $\mathrm{SO}_{2}$ not only poses a serious threat to human health but also damages vegetation and ecosystems [15]. In 2020, the severe acute respiratory syndrome coronavirus 2 (SARSCoV-2) that caused the coronavirus disease (COVID-19) has spread rapidly across countries, leading to large numbers of human deaths and unpredictable economic loss. The severity of the symptoms of those with COVID-19 may be associated with PM exposure [16]: the potential mechanism is that inflammatory pathways in the small respiratory airways are activated when the COVID-19 patients are exposed to PM, which leads to inflammatory cell recruitment and affects the prognosis of COVID-19 patients [17]. Recent studies found that air quality has improved significantly during the lockdowns due to the COVID-19 pandemic. Li et al. [18] reported that changes in the Air Quality Index (AQI) corresponded to different response levels determined by the different levels of administrative restrictions. They found that the concentrations of different pollutants were not statistically significantly different except for $\mathrm{NO}_{2}$ during the second- and third-level pandemic responses. Xian et al. [19] found that the synergistic effect of meteorological conditions and heterogeneous chemistry on the particulate pollution formation was still uncertain. Therefore, they could not confirm a certain relationship between the COVID-19 and PM exposure. The lockdowns may have had substantial short-term health benefits but did not improve the environment in the long term because local air quality is affected by local sources and transported pollutants [20]. Filonchyk and Peterson [21] confirmed that background sources significantly contributed to air pollution, even if human activities were severely reduced.

Air quality evolves with time and space evolution and so has different characteristics at different times and in different places. Huang et at. [22] found that $\mathrm{PM}_{2.5}$ had different characteristics at different times and seasons. The daily and monthly $\mathrm{PM}_{2.5}$ values showed U-shaped patterns, and the seasonal value of $\mathrm{PM}_{2.5}$ was high in winter but low in summer, with spring and autumn values being in between. The spatial distribution of the $\mathrm{PM}_{2.5}$ concentration mainly followed a northeast-southwest direction, and the air quality in North China was significantly worse than that in South China. The air quality of a region is affected not only by its own region's activities but also by those in other regions. This is because the atmospheric circulation processes influence the extent and direction of air mass transfer; hence, air pollutants are transported from one place to another [4]. Numerous studies have been conducted to identify air pollutant transport and trajectories over different regions of the world [23-29]. Yu et al. [30] used the HYSPLIT model to study the pollution characteristics of 29 cities in the Central Plains Economic Zone (CPEZ). They found that most serious air pollution may occur when air masses were transported from Shaanxi Province, Hubei Province, Anhui Province, and the northwest of the CPEZ. Hence, air pollution in Zhengzhou may originate from both long-distance transmission and local emissions. Filonchyk and Yan [31] studied the characteristics of six principal atmospheric pollutants in the city of Lanzhou. Their results from backward trajectory analysis showed that the air pollution may be transported from the north, northwest, and west directions. Li et al. [32] adopted the HYSPLIT model to explore air pollution in Qingdao, Shandong province. They found that the main factors resulting in air pollution were coal combustion and vehicular, domestic, and industrial emissions. Vehicular emissions and liquefied petroleum gas (LPG) and solvent usage also led to air pollution in Xiamen city. The air pollutants from Southeast China were transported to Xiamen via Fuzhou and affected the local environment [33]. Other researchers also found that industrial emissions, vehicular emissions, and trans-boundary pollution were important factors influencing air quality $[34,35]$. Punsompong and Chantara [36] used the backward trajectory analysis to investigate the percent contribution of emissions from local and trans-boundary to air pollutant concentrations. The results showed that the major factor of increasing the $\mathrm{PM}_{10}$ concentration in Northern Thailand was open biomass 
burning in Myanmar. Domestic biomass-burning aerosols that were transported from Central Thailand and Northeast Thailand affected the ambient air in Bangkok, Thailand, during the 2018-2019 haze episodes [37]. The long-range transport of the products of biomass burning affected ambient air in other regions [38, 39].

Most studies used the potential source contribution function (PSCF) and concentration weighted trajectory (CWT) to identify the sources of air pollution in a region. However, these two methods do not consider the degree of influence of each source on the region. The multifractal method is non-linear and can be used to analyze the degree of influence of one time series on another by investigating the coupling correlations of two time series. Multifractal detrended fluctuation analysis (MF-DFA) proposed by Kantelhardt et al. [40] has been widely adopted to identify the source of time series $[41,42]$. There are two main sources of multifractality: long-range correlations and fat-tailed probability distributions of time series. Zhou [43] firstly used the multifractal detrended cross-correlation analysis (MFDCCA) to explore multifractal cross-correlations. The strength of multifractality can be regarded as an indicator to reflect the closeness of the connection between two time series, which could be used to obtain the degree of influence of one time series on another [44]. The coupling detrended fluctuation analysis (CDFA) proposed by Hedayatifar et al. [45] is an extension of MF-DCCA that can be used to reflect the degree of influence by investigating the coupled correlations among several time series.

The multifractal cascade model was used to analyze the multifractal characteristics of ozone concentration time series in Taipei. The results showed that multifractal characteristics existed and other fractal methods should be used to further offer sound proof for the existence of a fractal nature [46]. Multifractal detrended fluctuation analysis (MF-DFA) was employed to analyze the multifractal nature of particulate matter (PM) concentrations from vehicle emissions in Hong Kong. The results indicated that particulate matters showed long-term correlation behaviors. The particulate matters in the range of $d_{p}<5 \mu \mathrm{m}$ had strong multifractal characteristics, whereas the particulate matters in the range of $d_{p} \geq 5 \mu m$ had weak multifractal characteristics [47]. In addition, Liu et al. [48], Shen et al. [49], and Dong et al. [50] found multifractal characteristics based on the MF-DFA approach in mainland China. There are a few studies based on the MF-DCCA method in the field of environmental pollution. Zhang et al. [51] used MF-DCCA and multifractal asymmetric detrended cross-correlation analysis (MF-ADCCA) to investigate the cross-correlations of $\mathrm{PM}_{2.5}$ and meteorological factors. The results showed that the cross-correlations between $\mathrm{PM}_{2.5}$ concentration and four meteorological factors were multifractal and anti-persistent, and the strength of multifractality in Beijing was stronger than that in Hong Kong. Stan et al. [52] employed the multifractal multiscale detrended cross-correlation analysis (MM-DCCA) to explore the cross-correlations among ozone and some selected precursors and between each precursor and temperature. The results showed that both individual data and correlated series showed multifractal properties and persistent long-range correlations. Hurst exponents, scaling exponents, and multifractal spectra confirmed that the two time series had multifractal characteristics in two time series, which implied the existence of non-linear cross-correlations between respiratory diseases and haze in South Korea. The main source of multifractality was fat-tailed distributions [53].

In this study, we adopted the backward trajectory model and multifractal methods to analyze the air pollution time series in Zhengzhou, Henan Province, China. We use the daily AQI index and six daily average concentrations of $\mathrm{PM}_{2.5}, \mathrm{PM}_{10}, \mathrm{SO}_{2}, \mathrm{CO}, \mathrm{NO}_{2}$, and $\mathrm{O}_{3}$ in five cities from December 2019 to February 2020.

The remainder of this paper is organized as follows. Section 2 introduces the methodology. Section 3 describes the data sources. Section 4 presents the empirical results, and Section 5 provides the conclusions.

\section{Materials and Methods}

2.1. HYSPLIT Model and Cluster Analysis. In order to identify the air pollutant trajectory, we used the Hybrid Single-Particle Lagrangian Integrated Trajectory (HYSPLIT) model developed by the National Oceanic and Atmospheric Administration (NOAA), USA. According to the NOAA, the HYSPLIT model uses either puff or particle approaches to calculate trajectories, dispersion, and deposition. The model associates the mass of the pollutant species with the release of either puffs, particles, or a combination of both to calculate air concentrations. Air concentrations are calculated for each grid cell of advection and diffusion, and the advection and diffusion of particles are computed from their initial location. We collected data from the global data assimilation system (GDAS) from the NOAA National Centers for Environmental Prediction (NCEP) to calculate 72hour backward trajectories at a $500 \mathrm{~m}$ altitude. Cluster methods of air mass backward trajectories can be used to identify the major transport pathways. The three different approaches for time series clustering are raw-data-based approach, feature-based approach, and model-based approach. Trajectory clustering is a time series clustering problem. In this study, the raw-data-based method was used for the air pollutant trajectory clustering. We employed a $\mathrm{K}$-means cluster analysis based on the Euclidean distance to divide the air pollutant trajectories into five categories.

2.2. PSCF and CWT Analyses. In order to determine potential source regions, we used the potential source contribution function (PSCF) model and concentration weighted trajectory (CWT) model based on the HYSPLIT model. The PSCF is a conditional probability function; it can be calculated as the ratio of the number of trajectory endpoints that are higher than a given criterion value to the number of total endpoints in the grid cell. The method calculates the PSCF value in the grid cell $(i, j)$ as follows:

$$
\mathrm{PSCF}=\frac{m_{i j}}{n_{i j}},
$$


where $m_{i j}$ is the number of trajectory endpoints greater than a given criterion value in the grid cell $(i, j)$ and $n_{i j}$ is the total number of trajectory endpoints falling within the grid cell $(i, j)$.

We then used a weight function, $W\left(n_{i j}\right)$, multiplied into the PSCF value to better reflect the uncertainty in the values for these cells. $W\left(n_{i j}\right)$ is calculated as

$$
W\left(n_{i j}\right)=\left\{\begin{array}{l}
1.00\left(4 N<n_{i j}\right) \\
0.70\left(N<n_{i j} \leq 4 N\right) \\
0.42\left(0.5 N<n_{i j} \leq N\right) \\
0.05\left(n_{i j} \leq 0.5 N\right)
\end{array}\right.
$$

where $N$ is the average number of trajectories points of all grid cells that contain at least one trajectory and $n_{i j}$ is the total number of trajectory endpoints in each grid cell.

The PSCF method has been extensively used to identify the potential sources of air pollution $[53,54]$. However, the two grid cells may have the same PSCF value when sample concentrations are slightly or extremely higher than the criterion or extremely high. Therefore, the PSCF method struggles to distinguish strong sources from moderate sources. The CWT method can overcome the limitation of the PSCF method because it can reflect the degree of influence of different potential sources by calculating the trajectory-weighted concentration. The average weighted concentration in the grid cell $(i, j)$ is calculated as

$$
C_{i j}=\frac{1}{\sum_{l=1}^{M} T_{i j l}} \sum_{l=1}^{M} C_{l} T_{i j l} \text {, }
$$

where $C_{i j}$ is the average weighted concentration, $l$ is the index of the trajectory, $M$ is the total number of trajectories, and $T_{i j l}$ is the time spent in the grid cell $(i, j)$ by trajectory $l$.

2.3. Multifractal Method. We used coupling detrended fluctuation analysis (CDFA) to investigate the coupled correlations between several non-stationary time series. According to the CDFA method, we can perform the multifractal detrended fluctuation analysis (MF-DFA) with one time series of length $N$ and perform the multifractal detrended cross-correlation analysis (MF-DCCA) with two time series of length $N$. The CDFA method can be summarized as follows.

There are several time series $x_{t}^{1}, \ldots, x_{t}^{j}, \ldots x_{t}^{n}$, $i, j=1,2, \ldots, n$, where $n$ is the length of the series and $t$ is the $t$ th member of each time series. The CDFA method can be summarized as follows.

First, calculate the profile $X^{j}(i)=\sum_{t=1}^{i}\left(x_{t}^{j}-\overline{x_{t}^{j}}\right)$, where $x_{t}^{j}$ represents the mean value of the $k$ th time series.

Second, divide the profile $X^{j}(i)$ into $N_{s}=\operatorname{int}(N / s)$ nonoverlapping segments of equal length $s$. Since the length $N$ of each series is often not a multiple of the considered time scale $s$, a short part at the end of the profile may remain. In order not to disregard this part of the series, the same procedure is repeated starting from the opposite end. Thus, $2 N_{s}$ segments are obtained altogether. The CDFA method calculates the local trend $x_{v}^{j}(i)$ for each of the $2 N_{s}$ segments by a least-square fit of each series. Then, the detrended covariance is determined by

$$
F_{v}(s) \equiv \frac{1}{s} \sum_{i=1}^{S} \prod_{j=1}^{n}\left\{\left|X^{j}[(v-1) s+i]-x_{v}^{j}(i)\right|\right\},
$$

for $v=1,2, \ldots, N_{s}$ and

$$
F_{v}(s) \equiv \frac{1}{s} \sum_{i=1}^{s} \prod_{j=1}^{n}\left\{\left|X^{j}\left[N-\left(v-N_{s}\right) s+i\right]-x_{v}^{j}(i)\right|\right\},
$$

for $v=N_{s}+1, N_{s}+2, \ldots, 2 N_{s}$.

Third, average over all segments and obtain the $q$ th order fluctuation function as

$$
F_{x^{1}, \ldots, x^{n}}(q, s) \equiv\left\{\frac{1}{2 N_{s}} \sum_{v=1}^{2 N_{s}}\left[F_{v}(s)\right]^{q / n}\right\}^{1 / q},
$$

for $q \neq 0$ and

$$
F_{x^{1}, \ldots, x^{n}}(0, s) \equiv \exp \left\{\frac{1}{2 n N_{s}} \sum_{v=1}^{2 N_{s}} \ln \left[F_{v}(s)\right]^{q / n}\right\},
$$

for $q=0$.

Fourth, analyze the scaling behavior of the fluctuation function by observing the log-log plots of $F_{x^{1}, \ldots, x^{n}}(q, s)$ versus $s$. If the time series $x_{t}^{1}, \ldots, x_{t}^{j}, \ldots, x_{t}^{n}$ is long-range power law correlated, $F_{x^{1}, \ldots, x^{n}}(q, s)$ will increase for large values of $s$, as a power law of

$$
F_{x^{1}, \ldots, x^{n}}(q, s) \sim s^{h_{x^{1}, \ldots, x^{n}}(q)},
$$

where $h_{x^{1}, \ldots, x^{n}}(q)$ is the generalized scaling exponent of CDFA which can be obtained by computing the slope of the $\log$-log plots of $F_{x^{1}, \ldots, x^{n}}(q, s)$ versus $s$. When $h_{x^{1}, \ldots, x^{n}}(q)$ is constant for all $q$, coupled correlations will be monofractal. On the contrary, when $h_{x^{1}, \ldots, x^{n}}(q)$ varies with different $q$, coupled correlations indicate the presence of multifractality. Specifically, if $h_{x^{1}, \ldots, x^{n}}(q)>0.5$, the coupled correlation is persistent (positive), which indicates that an increase (decrease) is always followed by another increase (decrease). If $h_{x^{1}, \ldots, x^{n}}(q)<0.5$, the coupled correlation is anti-correlated (negative), which means that an increase (decrease) is always followed by another decrease (increase). If $h_{x^{1}, \ldots, x^{n}}(q)=0.5$, the time series displays random walk behavior.

Fifth, calculate the singularity spectrum to qualify the multifractality by using the relationship between $h(q)$ and the Renyi exponent $\tau(q)$.

$$
\tau(q)=q h_{x^{1}, \ldots, x^{n}}(q)-1 .
$$

Through a Legendre transform, the multifractal spectrum $f(\alpha)$ is defined as

$$
\begin{aligned}
\alpha & =h_{x^{1}, \ldots, x^{n}}(q)+q h_{x^{1}, \ldots, x^{n}}(q) \text { and } \\
f(\alpha) & =q\left[\alpha-h_{x^{1}, \ldots, x^{n}}(q)\right]+1,
\end{aligned}
$$

where $\alpha$ is the Holder exponent index and $f(\alpha)$ is the singularity spectrum. The width of the singularity spectrum can be used to estimate the strength of multifractality as 
TABLE 1: Total observation stations located in the five cities.

\begin{tabular}{|c|c|c|c|c|}
\hline Zhengzhou & Shijiazhuang & Jinan & Zibo & Luoyang \\
\hline Tobacco Factory & Staff Hospital & Cadre Reset Institute & People's Park & No. 2 Primary School \\
\hline Textile Machinery Factory & High Tech Zone & $\begin{array}{c}\text { Agricultural Scientific } \\
\text { Institute }\end{array}$ & $\begin{array}{l}\text { Dongfeng } \\
\text { Chemical Plant }\end{array}$ & Municipal Party School \\
\hline Banking College & Northwest Water Source & Development Zone & Shuangshan & Yuxi Hotel \\
\hline Water Supply Company & $\begin{array}{l}\text { Southwest Higher } \\
\text { Education }\end{array}$ & Chemical Factory & Weather Station & Henan Forestry School \\
\hline $\begin{array}{l}\text { Management Committee of } \\
\text { Economic Development Zone }\end{array}$ & Century Park & Seed Stocks & Putian Garden & $\begin{array}{l}\text { Management Committee of } \\
\text { Development Zone }\end{array}$ \\
\hline No. 47 Middle School & People's Hall & Machine Tool Plant & Sanjin Group & $\begin{array}{c}\text { New Office Area of } \\
\text { Municipal Party Committee }\end{array}$ \\
\hline Municipal Monitoring Station & Fenglong Mountain & $\begin{array}{l}\text { Municipal Monitoring } \\
\text { Station }\end{array}$ & & $\begin{array}{c}\text { Kaixuan Road Primary } \\
\text { School }\end{array}$ \\
\hline Gangli Reservoir & $\begin{array}{l}\text { South-School Area of } \\
\text { No.22 Middle School }\end{array}$ & $\begin{array}{l}\text { Changqing Party } \\
\text { School }\end{array}$ & & \\
\hline Gangli Reservoir (Reference Site) & & $\begin{array}{l}\text { Technical College } \\
\text { Taixing Company } \\
\text { Laiwu Campaign } \\
\text { Memorial Hall }\end{array}$ & & \\
\hline
\end{tabular}

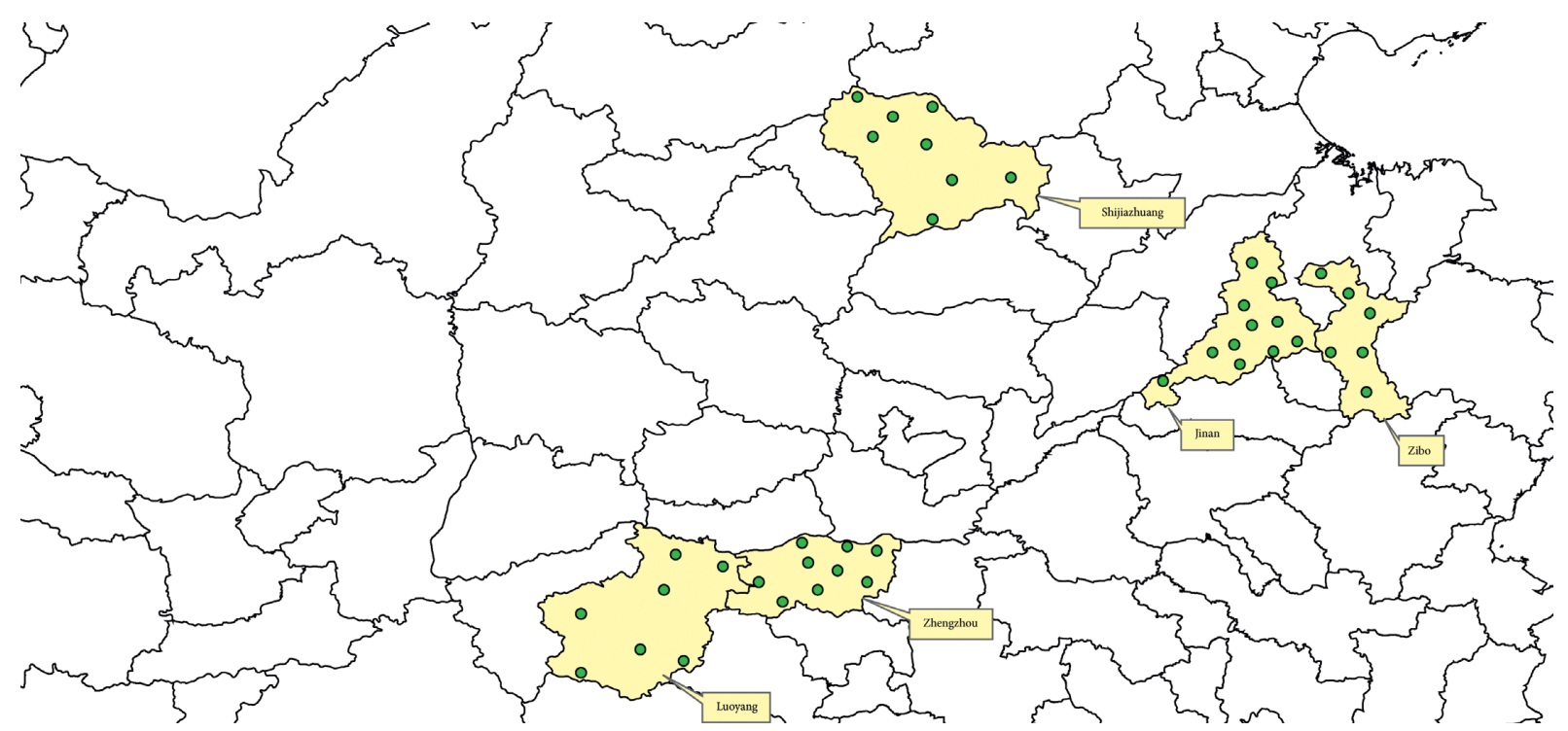

FIGURE 1: Geographic locations of the observation stations in the five cities.

$$
\Delta \alpha=\alpha_{\max }-\alpha_{\min }
$$

where $\Delta \alpha$ is the width of singularity spectrum. The greater the $\Delta \alpha$ value, the stronger the multifractality. In other words, a broad spectrum provides evidence for a strong multifractality nature, whereas a narrow one evidences for a weak multifractality nature.

2.4. Data Processing. In this study, we used the daily Air Quality Index (AQI) from 1 December 2019 to 29 February 2020. Air quality was estimated through the calculation of the daily Air Quality Index which was constituted by six main pollutants $\left(\mathrm{PM}_{2.5}, \mathrm{PM}_{10}, \mathrm{O}_{3}, \mathrm{SO}_{2}, \mathrm{NO}_{2}\right.$, and $\mathrm{CO})$. The AQI and index of the six main pollutants index in Zhengzhou, Shijiazhuang, Jinan, Zibo, and Luoyang were considered in our study. They were all obtained from the air quality publishing platform of China (https://www.resdc.cn/).

Table 1 lists the total observation stations in the five cities. According to Table 1, there were 9 observation stations in Zhengzhou, 8 in Shijiazhuang, 11 in Jinan, 6 in Zibo, and 7 in Luoyang. We indicate the locations of the observation stations mentioned in a geographic map in Figure 1.

Figure 2 shows the time series variation in the daily AQI in the five cities. The AQI value in Shijiazhuang is generally higher than that in the other cities. A similarity in the trends exists in the five AQI time series.

The descriptive statistics of the daily AQI are listed in Table 2. The standard deviation of the AQI time series in 


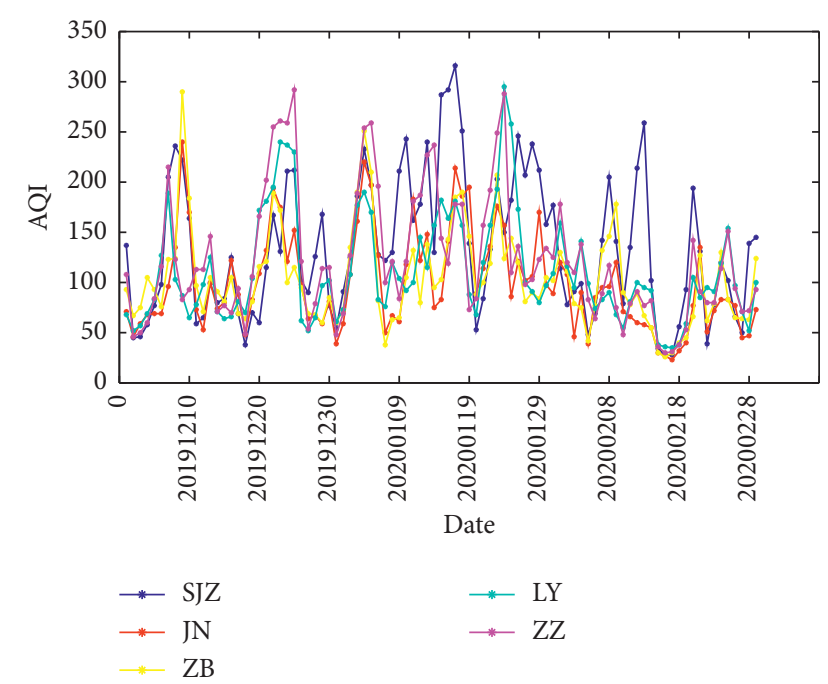

Figure 2: Daily Air Quality Index (AQI) from 1 December 2019 to 29 February 2020. SJZ, JN, ZB, LY, and ZZ refer to five cities, Shijiazhuang, Jinan, Zibo, Luoyang, and Zhengzhou, in China, respectively.

Shijiazhuang was the largest, indicating that the daily air quality had highest volatility. The skewness and kurtosis coefficient of each time series showed that each of the five AQI time series had non-normal distribution.

\section{Results}

3.1. HYSPLIT Analysis. We calculated the three-day (72hour) backward trajectories for every hour at an arrival altitude of $500 \mathrm{~m}$ in Zhengzhou city in Henan Province for December 2019, January 2020, and February 2020 using the HYSPLIT model. Zhengzhou, located in the hinterland center of the central plains in China, is heavily polluted and has high levels of particulate air pollution given the expanding population and rapidly developing economy.

We then divided the trajectories into five groups, Cluster1, Cluster2, Cluster3, Cluster4, and Cluster5, according to their origin and length using a K-means cluster analysis based on the Euclidean distance. Figures 3-5 show the five groups of trajectory clusters, respectively.

In December 2019, the clusters came from four different directions. Cluster 1 accounted for $22.31 \%$ of air masses mainly coming from the middle area of Shandong Province. Cluster 2 (19.76\%) had short transport patterns, mainly coming from the middle of Henan Province. Cluster 3 (12.63\%) was from northern Shanxi and passed through southern Hebei. Trajectories in Cluster 4 (28.23\%) were typically long trajectories, which originated in the mid-west area of Inner Mongolia and were transported across northern Ningxia, Northern Shaanxi, and southern Shanxi. Clusters 3 and 4 are accounted for $40.86 \%$ of the air masses, indicating that air masses mostly moved from northwestern direction. Cluster $5(17.07 \%)$ was from the middle area of Shaanxi Province and is across southern Shanxi.

We identified five air mass clusters coming from three directions in January, 2020. Cluster 1 accounted for $8.33 \%$, which originated from Northern Shaanxi and passed through the mid-west area of Shanxi Province. Cluster 2 $(16.13 \%)$ was mainly from the middle-south area of Hebei Province and transported across northern Henan. Cluster 3 (4.44\%) was characterized by the longest trajectories, being transported from the middle-west area of Inner Mongolia to Zhengzhou via northern Ningxia, Northern Shaanxi, and southern Shanxi. Cluster $4(47.58 \%)$ refers to the main pollution masses starting from northern Henan. Cluster 5 (23.52\%) was mainly from northwestern part of Henan. Clusters 3 and 4 were from different directions in Henan, showing that the air pollution was mainly from the local area.

In February 2020, we identified five air mass clusters coming from four directions. Cluster 1 (17.67\%) was mainly from the Bohai Rim region and eastern Shandong and passed through eastern Henan. Cluster 2 (12.64\%), was from the middle area of Inner Mongolia, traveled through Northern Shaanxi and southern Shanxi, and then arrived at Zhengzhou. Cluster $3(8.33 \%)$ was mainly from southwestern part of Hebei. Cluster 4 (17.82\%) was from Northern Shaanxi and passed through southern Shanxi prior to arriving in Zhengzhou. Cluster 4 and Cluster 2 were from the same direction. Cluster 5, accounting for $43.53 \%$ of the air masses and mainly starting from the southwestern part of Henan, refers to the main pollution masses.

The PSCF and CWT models were then applied to backward trajectories in order to identify potential source regions. The results of PSCF and CWT analyses for air pollution of Zhengzhou are shown in Figure 6. The highest PSCF values were obtained from the middle-western Henan, southern Hebei, and eastern Shandong. The plausible explanation is that the air pollutants originating from other regions may have accumulated and remained in this inland area for a while in winter due to the thermal stability and slow air movement. On the other hand, China is one of the countries that use coal as the main energy, and coal plays an important role in economic and social development. The enhanced coal combustion from heating in winter increases emission rate of air pollutants during the heating period [55-57]. As a result, the anthropogenic emission from coal burning has a major impact on pollutant concentrations. We further used the CWT model to reveal the potential source areas. The results also showed that the major potential source areas were the middle-western Henan, southern Hebei, and eastern Shandong areas.

Since Shijiazhuang, Jinan, Zibo, and Luoyang showed higher concentrations of the air pollution than other areas in the middle-western Henan, southern Hebei, and eastern Shandong, we choose these four representative cities to explore how close the air pollution of Zhengzhou is to other areas.

\subsection{Fuzzy Multifractal Analysis}

3.2.1. Fuzzy Multifractal Detrended Fluctuation Analysis. After identifying the source regions, we used the multifractal methods to investigate how close the air pollution of Zhengzhou was to that of each of other four cities. We first 
TABle 2: Descriptive statistics of daily AQI.

\begin{tabular}{|c|c|c|c|c|c|c|}
\hline City & Minimum & Maximum & Mean & Standard deviation & Skewness & Kurtosis \\
\hline Shijiazhuang & 28 & 316 & 134.868 & 69.532 & 0.497 & -0.585 \\
\hline Jinan & 23 & 240 & 98.879 & 48.787 & 0.861 & 0.162 \\
\hline Zibo & 26 & 290 & 103.461 & 48.178 & 1.293 & 2.282 \\
\hline Luoyang & 35 & 295 & 110.956 & 53.523 & 1.163 & 1.116 \\
\hline Zhengzhou & 30 & 292 & 122.561 & 63.582 & 0.964 & 0.239 \\
\hline
\end{tabular}

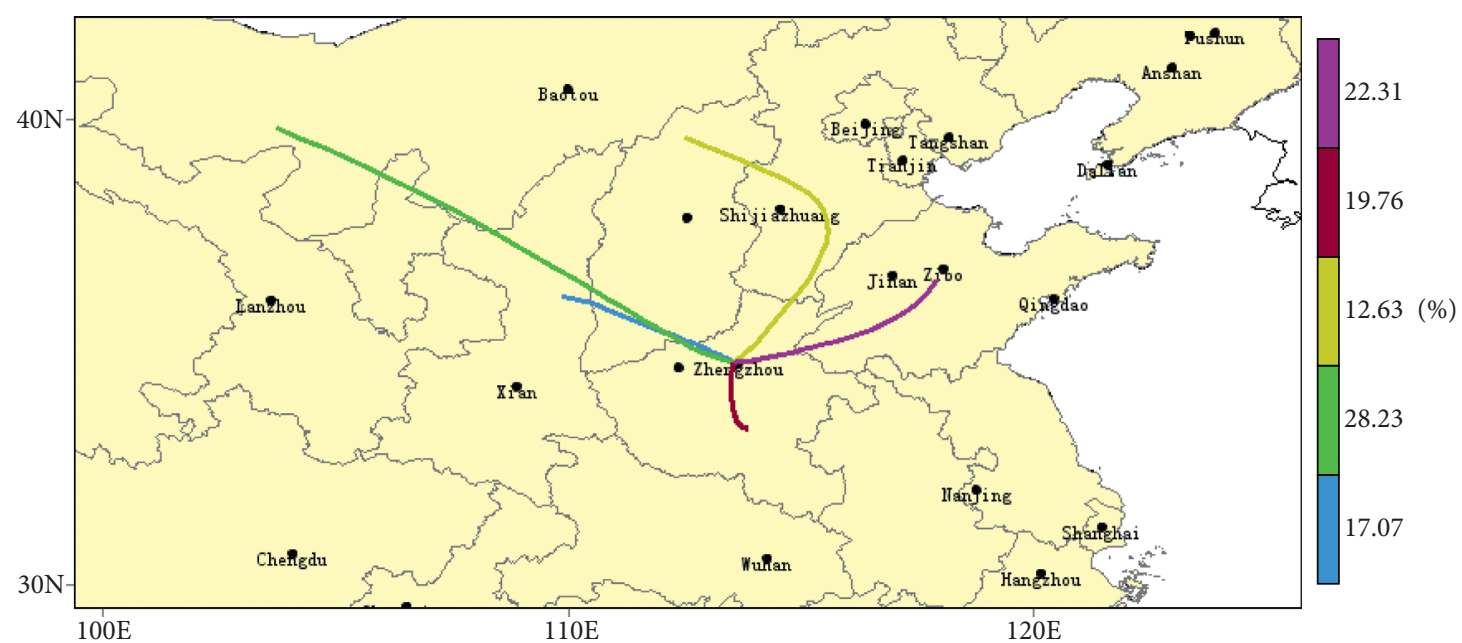

Figure 3: Trajectory of air mass clusters arriving in Zhengzhou in December 2019.

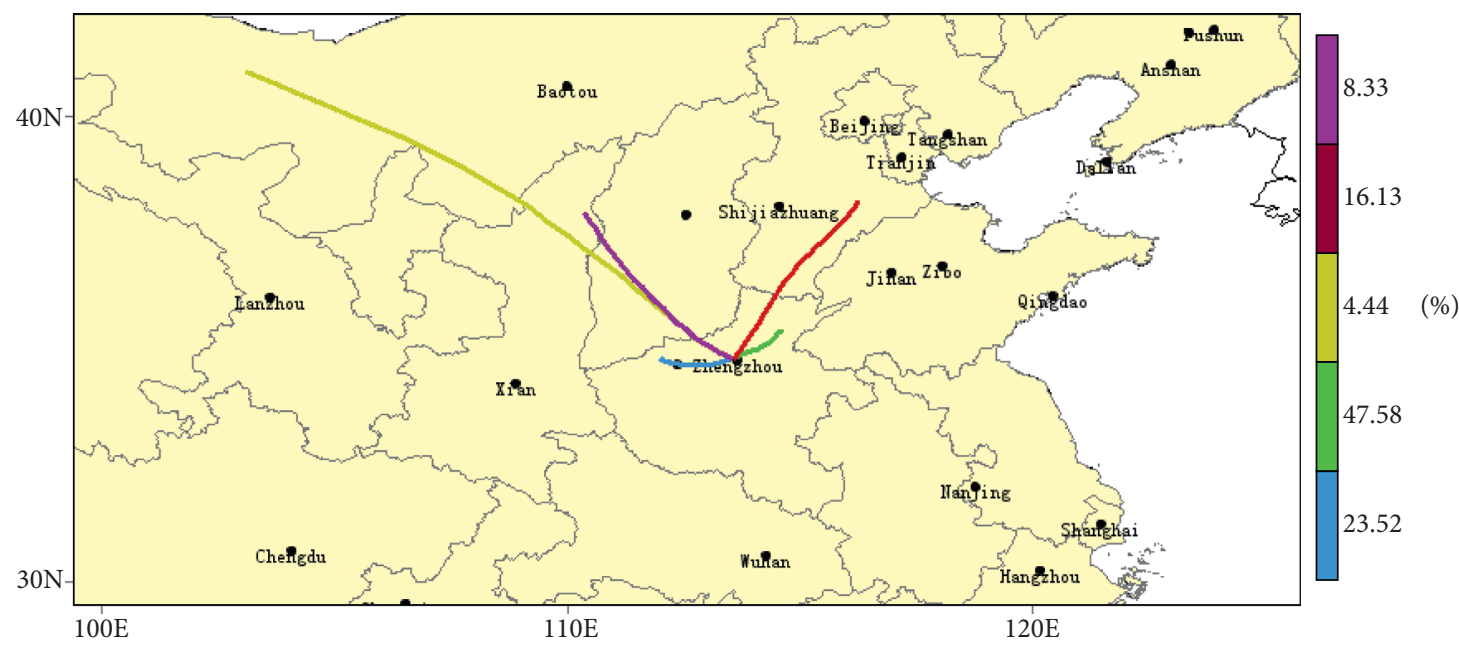

FIgURE 4: Trajectory of air mass clusters arriving in Zhengzhou in January 2020.

used the MF-DFA method to explore if multifractal characteristics existed in the air polluted time series of Zhengzhou. We performed the MF-DFA analysis for the AQI time series. The results are shown in Figure 7.

The range of time scale $s$ was set ranging from 10 events to $(N / 4)$ events, where $N$ is the length of AQI time series. The log-log plots of $F(q, s)$ versus $s$ for $q$ when the polynomial order $m=1$ are shown in the left part of Figure 7. It is evident that almost each line can fit the curve of fluctuation functions well for each $q$. This implies that a power-law function relation exists between $F(q, s)$ and $q$. Hence, the AQI time series has a multifractality nature. The generalized scaling exponent, $h(q)$, can be obtained by calculating the slopes of $\ln (F(q, s))$ against time scale $\ln (s)$ based on equations (4)-(8). The right part of Figure 7 shows the $h(q)$ value when $q$ varies from -10 to 10 for the AQI time series. All $h(q)$ values decrease as $q$ varies from -10 to 10 , which also confirms that the AQI time series has multifractal characteristics.

The Renyi exponent $\tau(q)$ and singularity spectrum $f(\alpha)$ were calculated based on equations (9) and (10). The plot of $\tau(q)$ versus fluctuation order $q$ and $f(\alpha)$ versus $\alpha$ is displayed in Figure 8. The plot of $\tau(q)$ is convex rather than a straight line. The non-linear nature proves the existence of 


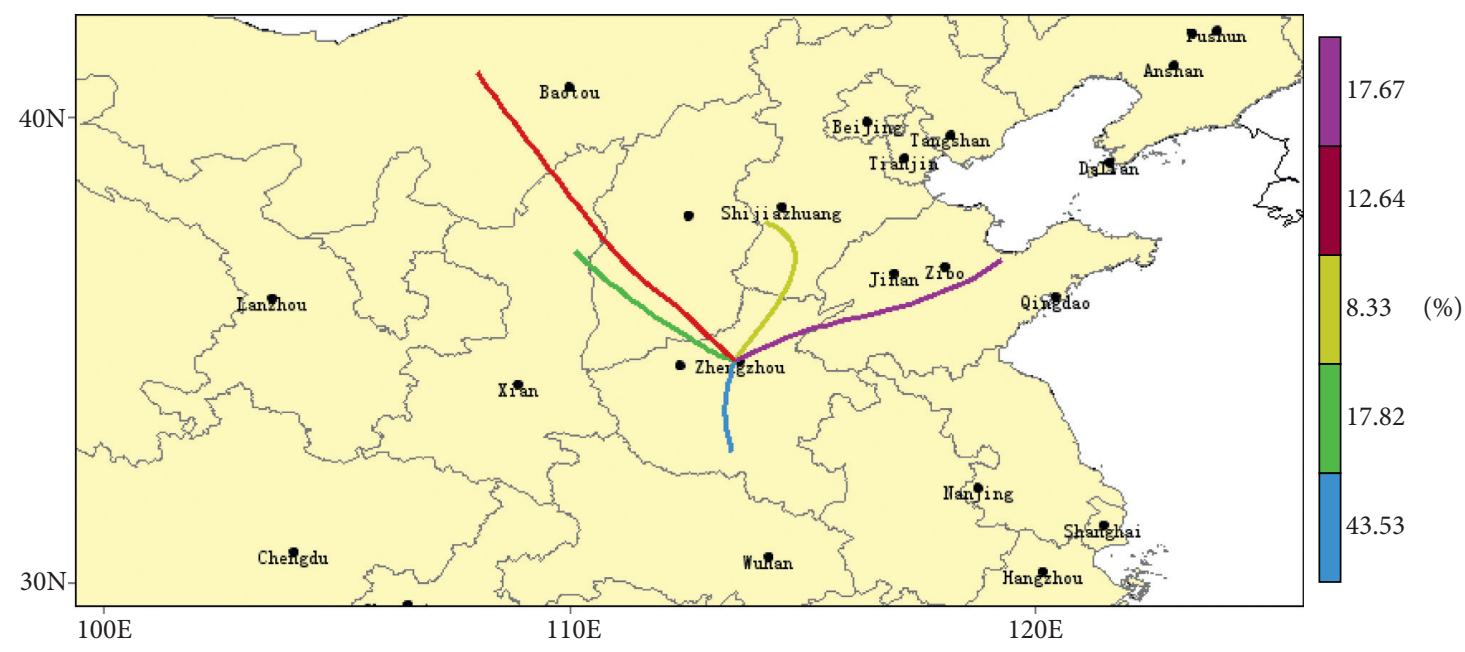

FIGURE 5: Trajectory of air mass clusters arriving in Zhengzhou in February 2020.

multifractality. The width of the multifractal spectrum, $f(\alpha)$, is significantly non-zero, indicating that the AQI time series are multifractal in nature.

\subsubsection{Multifractal Detrended Cross-Correlation Analysis.} In order to investigate how close the air pollution of Zhengzhou is to that of each of other four cities, we used the MF-DCCA method in this section. We firstly investigated if the cross-correlations existed between the air pollution in Zhengzhou and that in the other four cities using a cross-correlation statistic proposed by Podobnik et al. [58] The cross-correlation statistic between two series $x(i)$ and $y(i)$ of equal length $N$ was calculated as follows:

$$
X_{i}=\frac{\sum_{k=i+1}^{N} x_{k} y_{k-i}}{\sqrt{\sum_{k=1}^{N} x_{k}^{2} \sum_{k=1}^{N} y_{k}^{2}}} .
$$

Then, the cross-correlation test statistic was calculated as

$$
Q_{c c}(m)=N^{2} \sum_{i=1}^{m} \frac{X_{i}^{2}}{N-i},
$$

where $Q_{c c}(m)$ is approximately $x^{2}(m)$ distributed with $m$ degrees of freedom. The null hypothesis is that none of the first $m$ cross-correlation coefficients is different from zero. If the cross-correlations do not exist between two time series, the cross-correlation test agrees well with the $x^{2}(m)$ distribution. If the cross-correlations test exceeds the critical value of the $x^{2}(m)$ distribution, the cross-correlations are significant at a certain significance level. Figure 9 shows the critical value of the $x^{2}(m)$ distribution at 5\% level of significance for the degrees of freedom varying from 1 to 1000 . The results showed that the cross-correlation statistic $Q_{c c}(m)$ of the four pairs was larger than (or close to) the critical value of the $x^{2}(m)$ at $5 \%$ level of significance. This indicated that cross-correlations existed between the AQI time series in Zhengzhou and that of each of the other four cities.
Secondly, we used the MF-DCCA method to quantitatively present the cross-correlations quantitatively between the air pollution in Zhengzhou and that in the other four cities. The range of time scale $s$ was also set ranging from 10 events to $N / 4$ events, where $N$ is the length of each AQI time series in the five cities. $h_{x y}(q)$ values with $q$ varying from -10 to 10 are shown in Table 3. All the cross-correlation exponents $h_{x y}(q)$ decrease with $q$ varying from -10 to 10 , indicating that the air pollution of Zhengzhou and that of four cities have multifractal characteristics. Moreover, the four $h_{x y}(q)$ values are greater than 0.5 when $q$ is equal to two, which means that the two correlated series are persistent or show long-range dependence.

Thirdly, we calculated the width of the multifractal spectrum based on equation (11). The results are shown in Table 4. The multifractal spectrum provides evidence of the existence of multifractality. Moreover, its width can be used to estimate the strength of multifractality. The greater the $\Delta \alpha$ value, the closer the connection of the air pollution in Zhengzhou to that of a specific city. The $\Delta \alpha$ value was the largest in Jinan, followed by Shijiazhuang, Zibo, and Luoyang. Hence, the air pollution in Zhengzhou is closest to that in Jinan, followed by Shijiazhuang, Zibo, and Luoyang. According to the air quality publishing platform in China, Shijiazhuang and Jinan are two of the top ten most polluted cities in China, and Zibo and Luoyang are also heavy polluted cities. The multifractal results agree with the statistical results reported by the air quality publishing platform in China. We therefore concluded that Shijiazhuang and Jinan play an important role in affecting the air pollution of Zhengzhou, and Zibo and Luoyang are less important.

3.2.3. Coupling Detrended Fluctuation Analysis. The MFDCCA method was used to qualify the cross-correlations of the air pollution in Zhengzhou and that in the other four cities after identifying the potential source regions using the HYSPLIT analysis. In this part, we used the coupling detrended fluctuation analysis (CDFA) method to further 
TABLE 3: Cross-correlation exponents $h_{x y}(q)$ for the air pollution in Zhengzhou and in four cities.

\begin{tabular}{lcccc}
\hline$q$ & SJZ & JN & ZB & LY \\
\hline-10 & 1.714 & 1.736 & 1.683 & 1.700 \\
-9 & 1.702 & 1.724 & 1.672 & 1.689 \\
-8 & 1.687 & 1.711 & 1.659 & 1.676 \\
-7 & 1.669 & 1.693 & 1.642 & 1.660 \\
-6 & 1.645 & 1.670 & 1.620 & 1.640 \\
-5 & 1.615 & 1.640 & 1.591 & 1.614 \\
-4 & 1.575 & 1.599 & 1.550 & 1.579 \\
-3 & 1.522 & 1.542 & 1.495 & 1.533 \\
-2 & 1.454 & 1.466 & 1.423 & 1.473 \\
-1 & 1.378 & 1.381 & 1.344 & 1.407 \\
0 & 1.303 & 1.302 & 1.275 & 1.345 \\
1 & 1.237 & 1.240 & 1.223 & 1.297 \\
2 & 1.177 & 1.183 & 1.179 & 1.257 \\
3 & 1.123 & 1.132 & 1.141 & 1.224 \\
4 & 1.080 & 1.090 & 1.109 & 1.195 \\
5 & 1.045 & 1.057 & 1.083 & 1.170 \\
6 & 1.018 & 1.031 & 1.061 & 1.151 \\
7 & 0.998 & 1.011 & 1.044 & 1.135 \\
8 & 0.982 & 0.995 & 1.030 & 1.122 \\
9 & 0.969 & 0.983 & 1.019 & 1.111 \\
10 & 0.959 & 0.972 & 1.009 & 1.102 \\
\hline
\end{tabular}

TABLE 4: $\Delta \alpha$ value of the air pollution in Zhengzhou and four other cities.

\begin{tabular}{lccc}
\hline & $\alpha_{\max }$ & $\alpha_{\min }$ & $\Delta \alpha$ \\
\hline SJZ & 0.823 & -0.134 & 0.957 \\
JN & 0.837 & -0.121 & 0.958 \\
ZB & 0.779 & -0.077 & 0.856 \\
LY & 0.794 & 0.022 & 0.772 \\
\hline
\end{tabular}

explore what was the role of the given air pollutant in the air pollution in the four cities. The Air Quality Index (AQI) is a dimensionless index that quantitatively describes air quality: the larger its value, the more serious the air pollution and the greater the harm to human health. Six main air pollutants involved in the construction of AQI are fine particulate matter $\left(\mathrm{PM}_{2.5}\right)$, inhalable particulate matter $\left(\mathrm{PM}_{10}\right)$, sulfur dioxide $\left(\mathrm{SO}_{2}\right)$, nitrogen dioxide $\left(\mathrm{NO}_{2}\right)$, ozone $\left(\mathrm{O}_{3}\right)$, and carbon monoxide (CO).

The range of time scale $s$ was set between 10 and $N / 4$ events, where $N$ was the length of each air pollutant's time series in the four cities. We obtained the $h_{x^{1}, \ldots, x^{n}}(q)$ values based on equations (4)-(8), where $x^{1}, \ldots, x^{n}$ refers to air pollutant time series in each of the four cities. The results are reported in Table 5, which shows that the $h_{x^{1}, \ldots, x^{n}}(q)$ values in the four cities decreased when the $q$ value increased. This means that the six air pollutant time series showed multifractality in each of the four cities.

The two main sources of multifractality are long-range temporal correlations for small and large fluctuations and fat-tailed probability distributions in fluctuations. We shuffled and phase-randomized the original series to identify the contribution of each source. The shuffling procedure can preserve the probability distribution of the original series but
TABLE 5: Values of the generalized $q$ th order Hurst exponents $h_{x^{1}, \ldots, x^{n}}(q)$.

\begin{tabular}{lcccc}
\hline & SJZ & JN & ZB & LY \\
\hline-10 & 2.210 & 2.348 & 1.281 & 2.470 \\
-9 & 2.198 & 2.336 & 1.271 & 2.457 \\
-8 & 2.182 & 2.320 & 1.258 & 2.441 \\
-7 & 2.162 & 2.301 & 1.242 & 2.420 \\
-6 & 2.136 & 2.274 & 1.222 & 2.392 \\
-5 & 2.099 & 2.237 & 1.198 & 2.353 \\
-4 & 2.048 & 2.182 & 1.169 & 2.297 \\
-3 & 1.968 & 2.094 & 1.134 & 2.207 \\
-2 & 1.826 & 1.932 & 1.097 & 2.038 \\
-1 & 1.492 & 1.550 & 1.058 & 1.613 \\
0 & 1.218 & 1.147 & 1.022 & 1.204 \\
1 & 1.142 & 1.065 & 0.991 & 1.112 \\
2 & 1.096 & 1.029 & 0.962 & 1.082 \\
3 & 1.056 & 1.002 & 0.937 & 1.060 \\
4 & 1.023 & 0.981 & 0.914 & 1.044 \\
5 & 0.996 & 0.962 & 0.894 & 1.031 \\
6 & 0.974 & 0.946 & 0.877 & 1.020 \\
7 & 0.956 & 0.933 & 0.863 & 1.011 \\
8 & 0.942 & 0.922 & 0.851 & 1.004 \\
9 & 0.930 & 0.912 & 0.841 & 0.998 \\
10 & 0.920 & 0.904 & 0.833 & 0.992 \\
\hline
\end{tabular}

TABLE 6: Width of multifractal spectrum value $\Delta \alpha$ for the original series, the shuffled series, and the surrogated series of four cities.

\begin{tabular}{lccc}
\hline City & $\Delta \alpha_{\text {original }}$ & $\Delta \alpha_{\text {shuffled }}$ & $\Delta \alpha_{\text {surrogate }}$ \\
\hline SJZ & 1.492 & 0.069 & 0.266 \\
JN & 1.627 & 0.125 & 0.276 \\
ZB & 0.624 & 0.174 & 0.203 \\
LY & 1.646 & 0.087 & 0.211 \\
\hline
\end{tabular}

destroy any temporal correlations. The shuffled series showed single fractal characteristics, that is, when the sources of multifractality were only from long-range temporal correlations, the generalized scaling exponent index $h(q)$ was 0.5 . The phase-randomization procedure can weaken the non-Gaussianity of the time series while leaving the correlation of the time series unchanged. The generalized scaling exponent index $h(q)$ processed by phase randomization was independent of $q$.

In order to identify the sources of multifractalities in the four cities, we shuffled and phase-randomized the original series and obtained a shuffled series and the surrogated series, respectively. The width of the multifractal spectrum of each time series is reported in Table 6 . The spectral widths of both the shuffled and surrogated series are smaller than those of the original series, indicating that long-range temporal correlations and fat-tailed probability distributions are the common causes of multifractality in the four cities. Moreover, the spectra widths of the shuffled series are smaller than those of the corresponding surrogated series in each city, which implies that long-range temporal correlations play an important role in multifractality, while fattailed probability distributions are less important. 

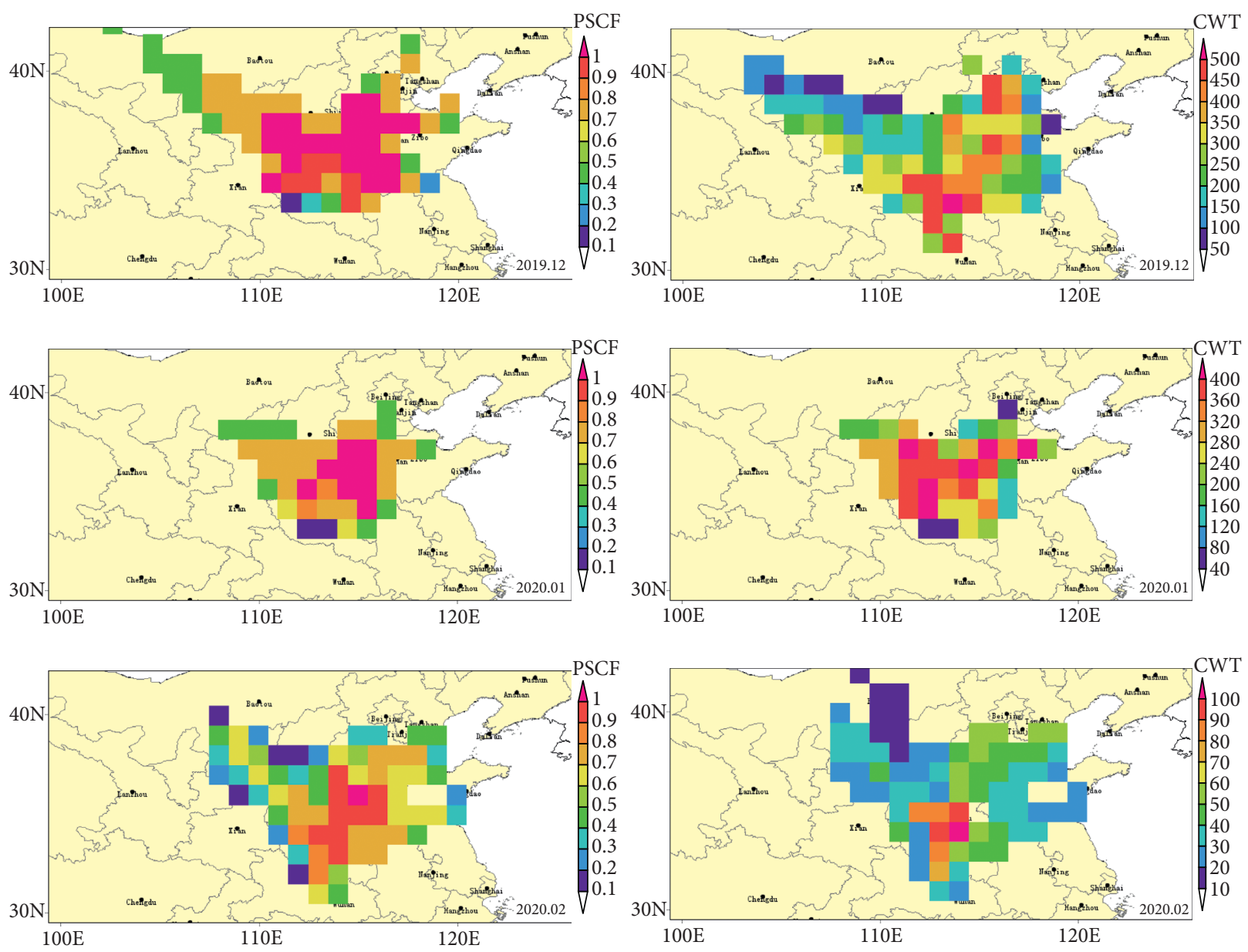

Figure 6: PSCF and CWT maps of Zhengzhou from December 2019 to February 2020.
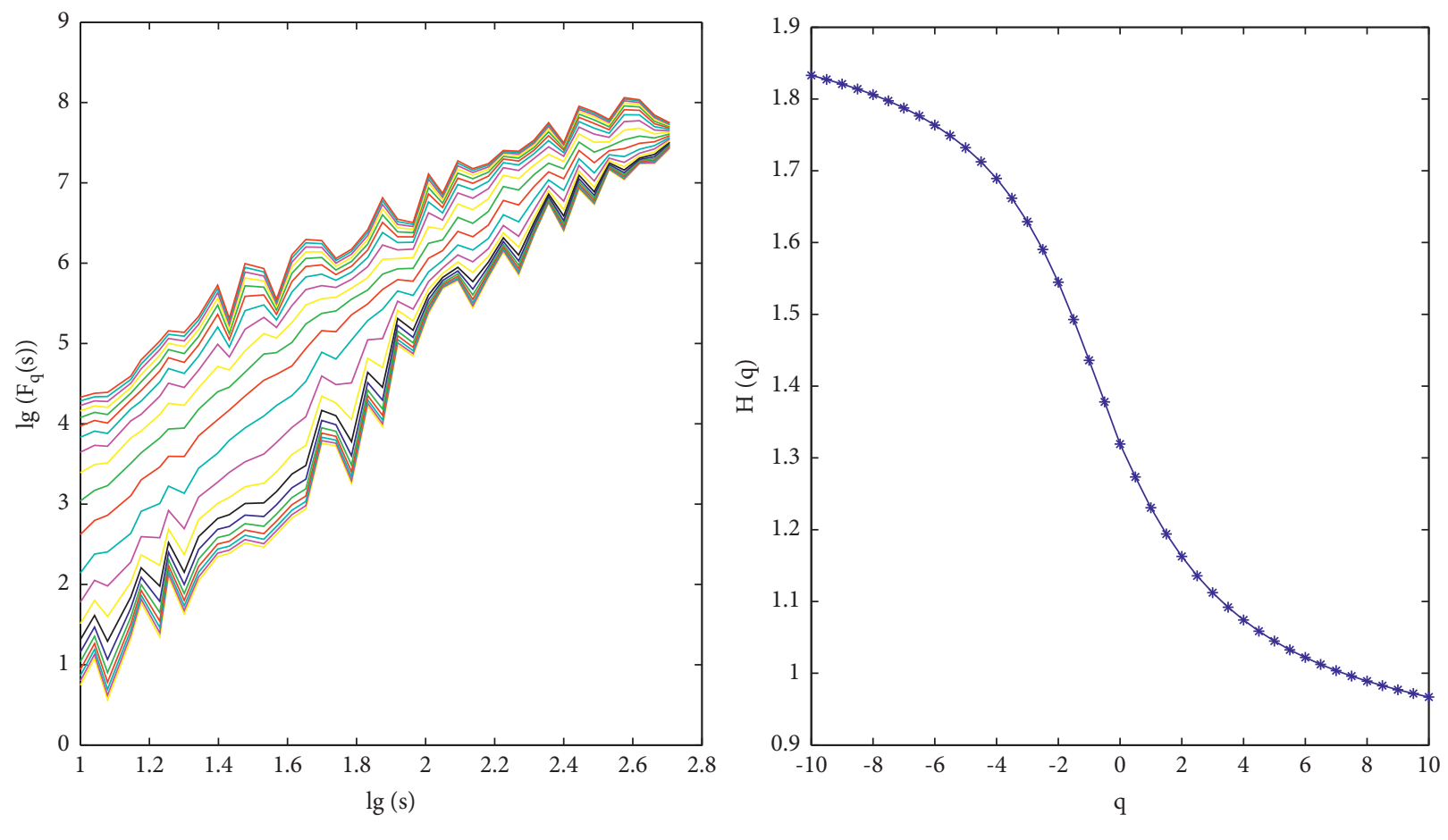

ZZ

$\rightarrow$ ZZ

Figure 7: Log-log plots of fluctuation functions $\ln (F(q, s))$ versus time scale $\ln (s)$ for AQI series in Zhengzhou (left part). Generalized Hurst exponent, $h(q)$, as a function of $q$ of AQI time series (right part). 


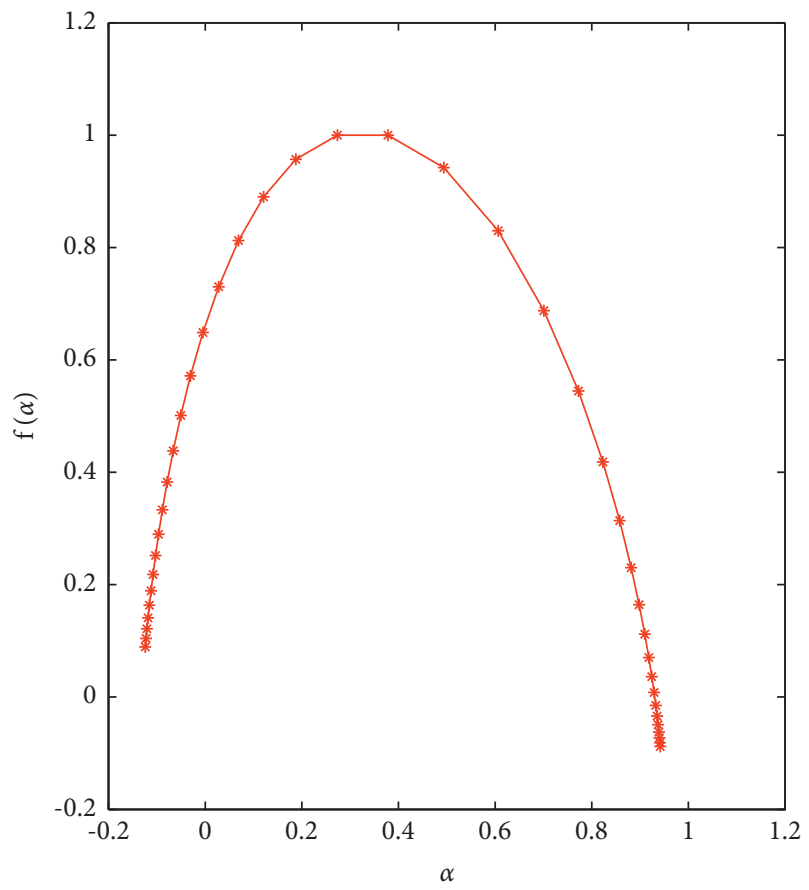

$\rightarrow * \mathrm{ZZ}$

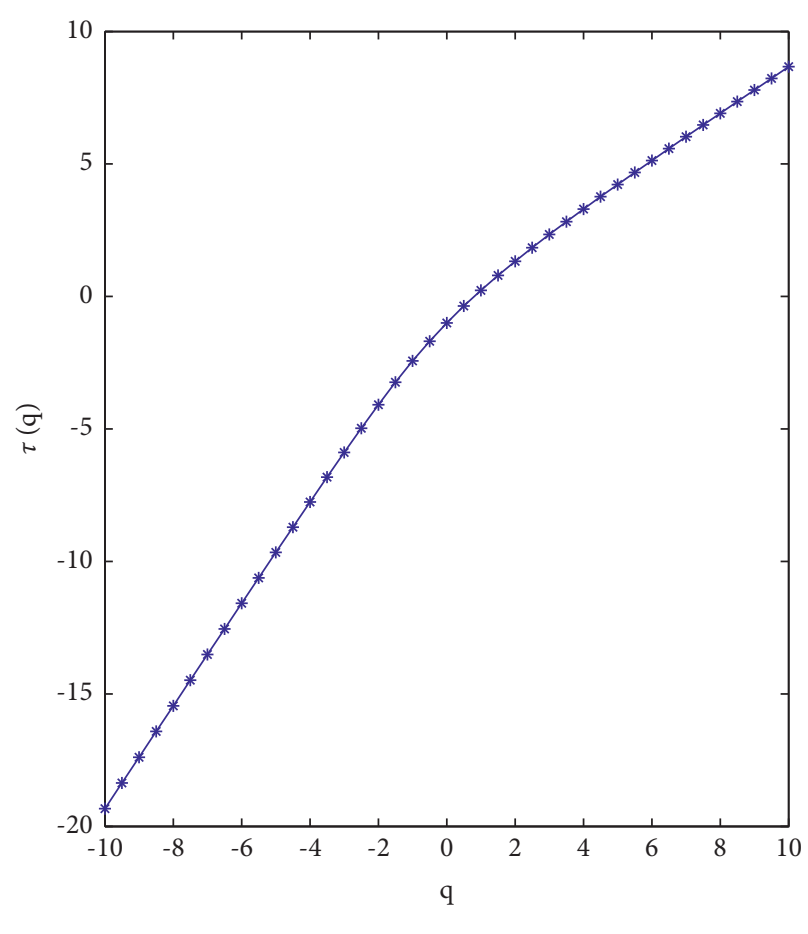

$\rightarrow-\mathrm{ZZ}$

FIGURE 8: Multifractal spectra $f(\alpha)$ and scaling exponents $\tau(q)$ of the AQI time series in Zhengzhou.

According to the above principle, we used either the shuffling or phase-randomization procedure to modify one of the air pollutants time series to identify the sources of the multifractality in the four cities. The difference in the generalized scaling exponent value between the original time series and the modified time series is due to either the longrange temporal correlations or fat-tailed probability distributions. The larger the difference is, the larger the contribution of one time series to the coupled correlations of six air pollutant time series will be. Hence, we investigated the role of the given air pollutant in air pollution of the four cities. Figures 10-13 show generalized scaling exponent values based on the shuffling procedure.

For Shijiazhuang and Jinan, carbon monoxide (CO) had the strongest impact on the air pollution, while sulfur dioxide $\left(\mathrm{SO}_{2}\right)$ had the smallest impact on the air pollution. Nitrogen dioxide $\left(\mathrm{NO}_{2}\right)$ played an important role in the air pollution of Jinan, but less so in Shijiazhuang. The impact of inhalable particulate matter $\left(\mathrm{PM}_{10}\right)$ on the air pollution in Zibo was the largest, followed by fine particulate matter $\left(\mathrm{PM}_{2.5}\right)$ and carbon monoxide $(\mathrm{CO})$. Ozone $\left(\mathrm{O}_{3}\right)$ had the smallest impact on the air pollution in $\mathrm{Zibo} ; \mathrm{SO}_{2}$ played a major role in affecting the air pollution in Luoyang.

Although fat-tailed probability distributions were less important than long-range temporal correlations in multifractality, Figures $14-17$ show the $h_{x^{1}, \ldots, x^{n}}(q)$ values based on the phase-randomization procedure. Carbon monoxide (CO) had the greatest impact on the air pollution, and sulfur dioxide $\left(\mathrm{SO}_{2}\right)$ had the smallest impact on the air pollution in Shijiazhuang and Jinan. Nitrogen dioxide $\left(\mathrm{NO}_{2}\right)$ more strongly affected the air pollution in Jinan than in Shijiazhuang. The result is inconsistent with the findings based

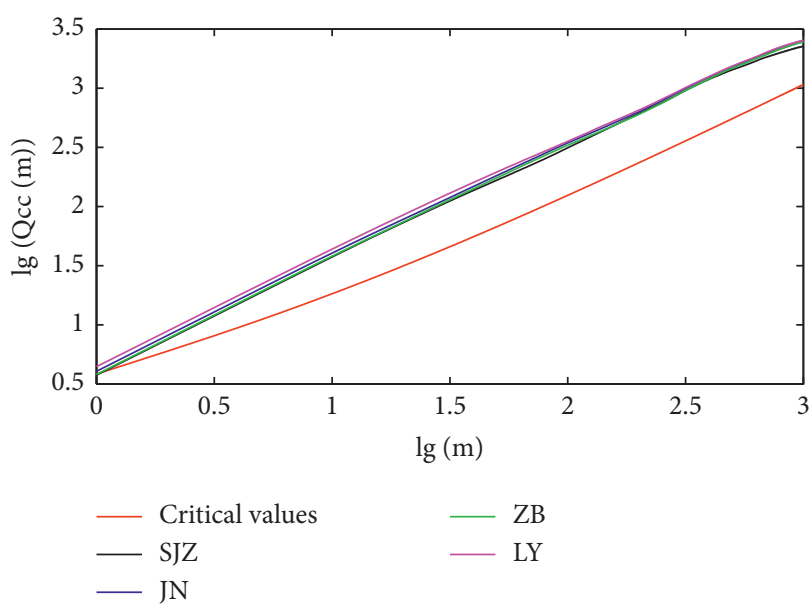

Figure 9: Cross-correlation statistic tests for the AQI series between Zhengzhou and each of the four other cities. The red line indicates the critical values (at $5 \%$ level of significance).

on the shuffled procedure. The impact of inhalable particulate matter $\left(\mathrm{PM}_{10}\right)$ on the air pollution was the largest in Zibo. We could not differentiate the contributions of $\mathrm{SO}_{2}$, $\mathrm{PM}_{2.5}$, and $\mathrm{CO}$ according to the figure in the $h_{x^{1}, \ldots, x^{n}}(q)$ value between the original time series, and each of these modified time series was approximately same. As for Luoyang city, $\mathrm{SO}_{2}$ had the largest impact on the air pollution. We still could not conclude which air pollutants contributed more to the air pollution.

The average concentrations of the air pollutants in Shijiazhuang, Jinan, Zibo, and Luoyang were higher than the national average. The average concentrations of carbon 


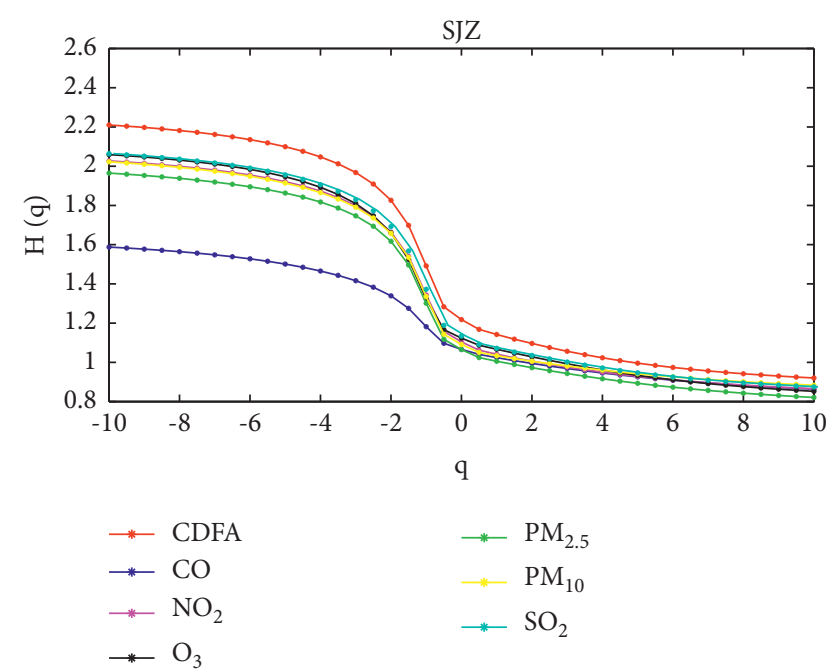

Figure 10: Shijiazhuang $H(q)$ values in the specified shuffled time series.

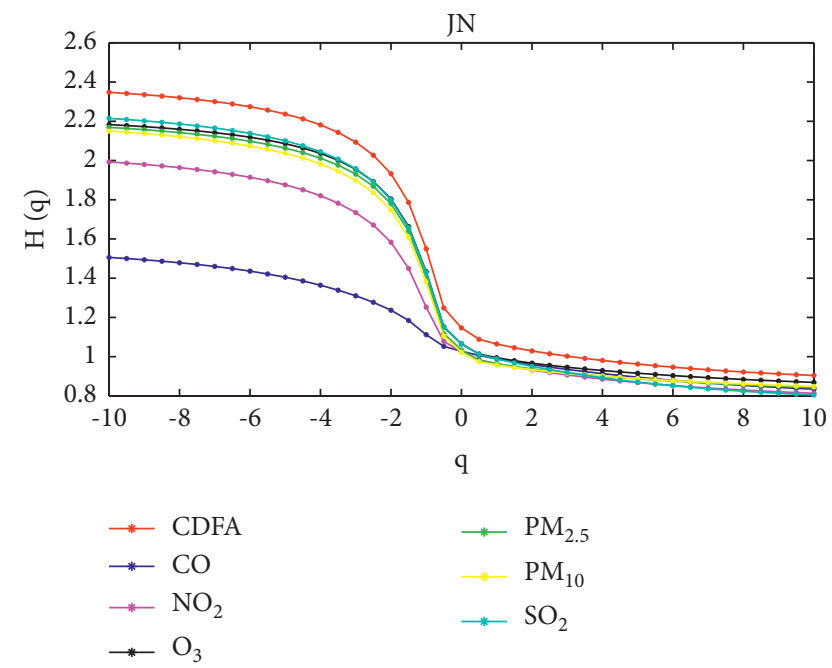

Figure 11: Jinan $H(q)$ values in the specified shuffled time series.

monoxide (CO) were the highest in Shijiazhuang, followed by Zibo and Jinan. The average concentrations of nitrogen dioxide $\left(\mathrm{NO}_{2}\right)$, inhalable particulate matter $\left(\mathrm{PM}_{10}\right)$, and fine particulate matter $\left(\mathrm{PM}_{2.5}\right)$ were generally high in the four cities. The average concentration of sulfur dioxide $\left(\mathrm{SO}_{2}\right)$ was the highest in Luoyang. The air pollution in these four cities could be characterized by obvious seasonal variation, that is, the air pollution is serious in winter, and less so in spring and autumn. The main reason for this finding is that these four inland cities are located in the north of China, where people burn coal for heating in winter. In winter, the weather is dry with little precipitation, light wind, and frequent inversion weather, which results in the minimal diffusion of the emissions of motor vehicles and coal difficult to diffuse. In addition to industrial emissions, vehicle emissions and

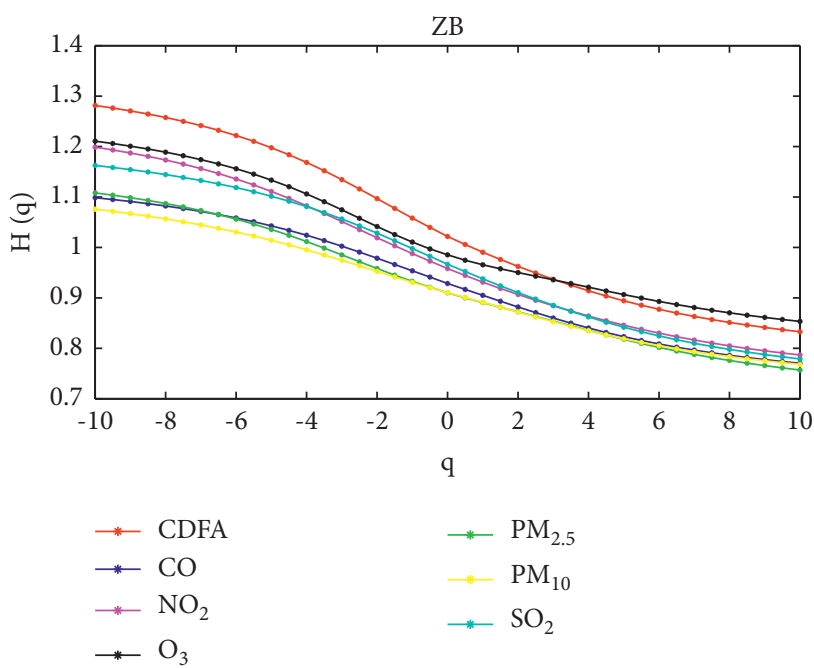

Figure 12: Zibo $H(q)$ values in the specified shuffled time series.

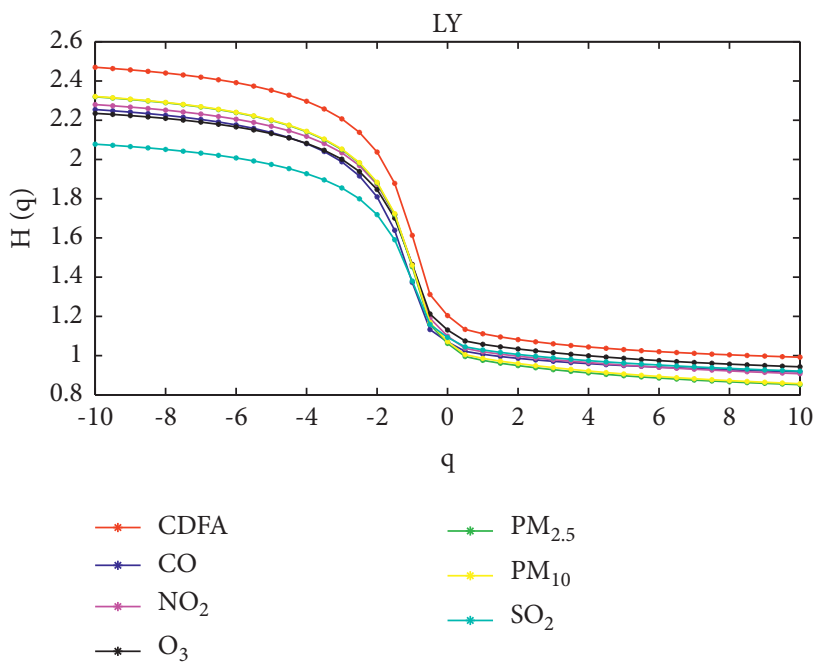

Figure 13: Luoyang $\mathrm{H}(\mathrm{q})$ values in the specified shuffled time series.

adverse meteorological conditions also exacerbate air pollution.

In summary, Jinan and Shijiazhuang have important impacts on the air pollution in Zhengzhou, followed by Zibo and Luoyang. Among these source regions, carbon monoxide $(\mathrm{CO})$, nitrogen dioxide $\left(\mathrm{NO}_{2}\right)$, and inhalable particulate matter $\left(\mathrm{PM}_{10}\right)$ had important influences on the air pollution. Sulfur dioxide $\left(\mathrm{SO}_{2}\right)$ had a small impact on the air pollution in Shijiazhuang and Jinan but a strong impact on the air pollution in Luoyang. Ozone $\left(\mathrm{O}_{3}\right)$ had the smallest impact on the air pollution in Zibo. The air pollutants may be transported to Zhengzhou and affect local air quality. Carbon monoxide $(\mathrm{CO})$, nitrogen dioxide $\left(\mathrm{NO}_{2}\right)$, and inhalable particulate matter $\left(\mathrm{PM}_{10}\right)$ played a major role in 


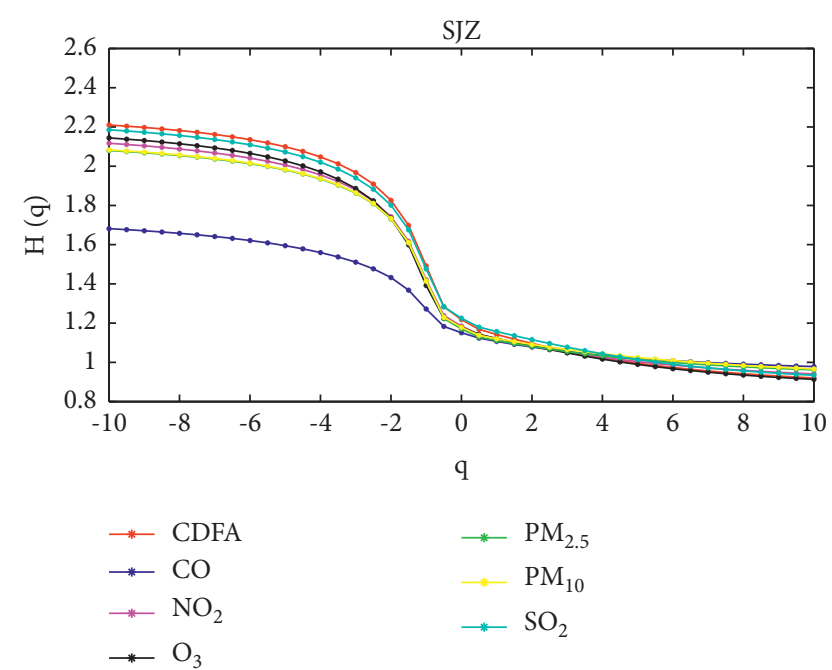

Figure 14: Shijiazhuang $H(q)$ values in the specified surrogate time series.

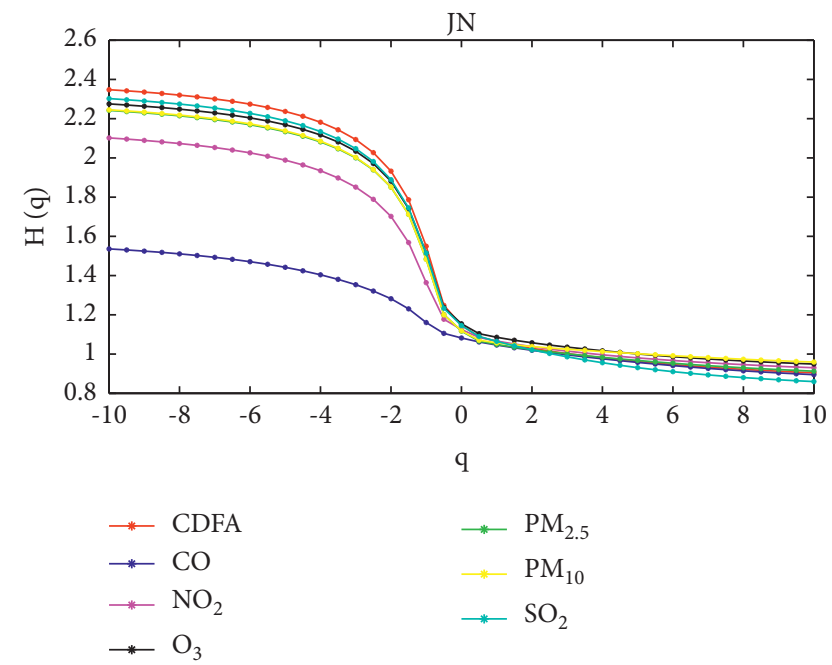

FIGURE 15: Jinan $H(q)$ values in the specified surrogate time series.

the air pollution, while sulfur dioxide $\left(\mathrm{SO}_{2}\right)$ and ozone $\left(\mathrm{O}_{3}\right)$ may have played a minor role.

\section{Discussion}

In this study, we used multifractal methods combined with the backward trajectory model to study the air pollution in Zhengzhou. Compared to previous studies, we adopted several methods and investigated several air pollutants.

Using the HYSPLIT analysis, we calculated three-day backward trajectories for every hour at an arrival altitude of $500 \mathrm{~m}$ in Zhengzhou; subsequently, we classified the trajectories into five clusters. The results showed that the clusters of air masses mainly came from Shandong Province, Shaanxi Province, Shanxi Province, Inner Mongolia, Hebei Province, and Henan Province. Similar to the results of our

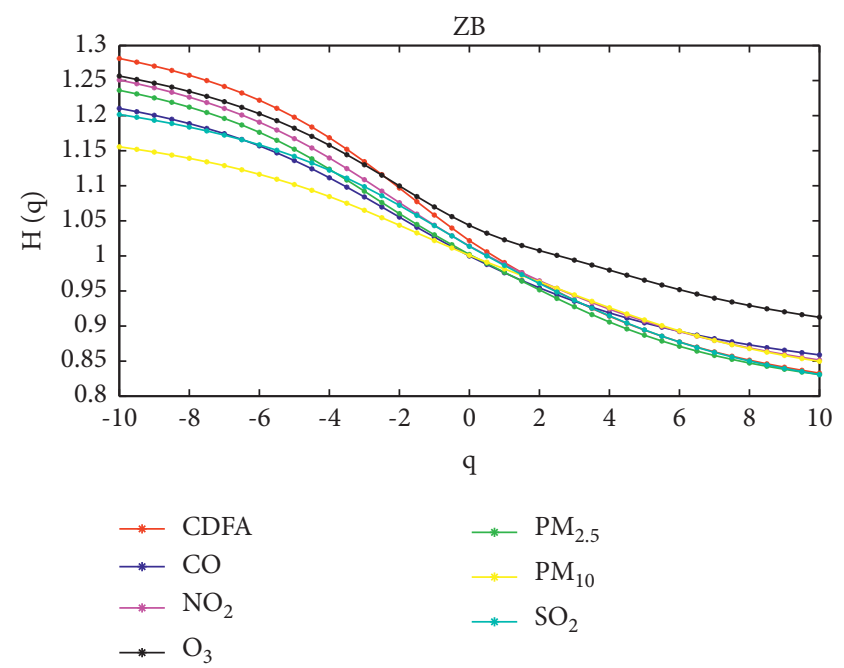

Figure 16: Zibo $H(q)$ values in the specified surrogate time series.

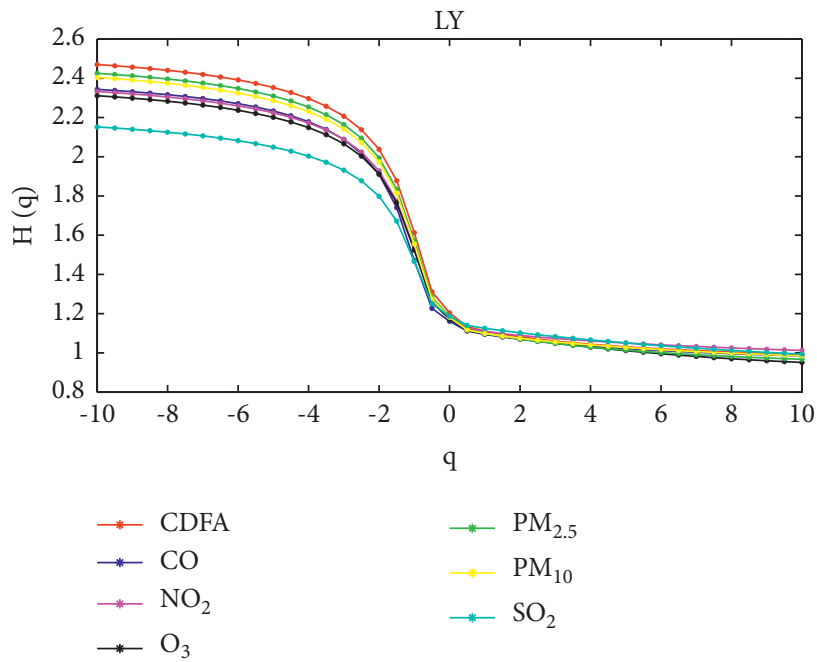

FIgURE 17: Luoyang $H(q)$ values in the specified surrogate time series.

present study, a previous study found that some trajectories arriving at Hefei, an inland city in Central China, were mainly from Shandong Province, in addition to Liaoning Province, Jiangsu Province, and Hefei city [59].

Comparing the results in three different months, the directions of the five air mass clusters did not change significantly. In December 2019, the clusters were from four different directions: northwest, northeast, north, and south. There were five air mass clusters from three directions in January 2020, which are northwest, northeast, and west. In February 2020, there were five air mass clusters from four directions of northwest, northeast, and south.

Previous studies have reported that the air pollutant concentration may increase because of anthropogenic combustion for heating purposes. The wind direction is an important factor affecting the aerosol transported from areas 
where biomass is openly burned area, leading to the transboundary and local air pollution transport [26, 37, 60]. For this reason, the large amount of burning coal to create heat in winter causes environmental pollution. In our study, the results of PSCF and CWT analyses showed that the potential source areas are mainly middle-western Henan, southern Hebei, and eastern Shandong. The sample period was December, January, and February, which was winter in north Yangtze River area in China. The emission rate of air pollutants may be increased by the increased amount of coal combusted for heating, and air pollutants may accumulate and remain in this area due to meteorological conditions [55-57]. Additionally, most backward trajectories indicated that the air pollutants were from neighboring provinces. This is consistent with the results of a previous study [54].

The log-log plots of $F(q, s)$ versus $s$ and the generalized Hurst exponent index were calculated with the MF-DFA method. The results showed that the AQI time series of Zhengzhou has multifractal characteristics. The Renyi exponent index and singularity spectrum confirmed that the results are stable. In the previous studies, persistent powerlaw correlations in $\mathrm{PM}_{10}$ and $\mathrm{O}_{3}$ fluctuations were detected in Baltimore, USA, which reflected short- and long-term meteorological features related to the self-organized critical behavior of the atmosphere [61]. Diosdado et al. [62] found that air pollutants' time series, inhalable particulate matter $\left(\mathrm{PM}_{10}\right)$, sulfur dioxide $\left(\mathrm{SO}_{2}\right)$, nitrogen dioxide $\left(\mathrm{NO}_{2}\right)$, ozone $\left(\mathrm{O}_{3}\right)$, and carbon monoxide $(\mathrm{CO})$ were multifractal in Mexico. Dong et al. [50] verified the existence of a significant power-law behavior and long-range correlations for the $\mathrm{PM}_{2.5}$ and $\mathrm{PM}_{10}$ series in Shanghai. Shen et al. [49] found that the daily Air Pollution Index (API) in Nanjing was multifractal. This indicates that the findings of our study are consistent with those of previous studies, proving important complementary information to previous studies.

We used the multifractal methods and the backward trajectory model to explore the cross-correlations between the air pollution in Zhengzhou and that in four other cities. Our multifractal study considered meteorological conditions, similar to a previous study [51]. They also investigated the multifractal characteristics of $\mathrm{PM}_{2.5}$ concentration combined with meteorological conditions in Beijing and Hong Kong. In contrast, they used specific meteorological factors such as temperature, air pressure, relative humidity, and wind speed to explore the cross-correlations between $\mathrm{PM}_{2.5}$ concentration and each of meteorological factors. Stan et al. [52] also presented the results of the cross-correlations between temperature and each of the several gases. They found that all correlated series had multifractal properties and persistent long-range correlations. Additionally, they conducted a fuzzy multifractal analysis of ozone and some precursors (nitrogen oxides (NOXs), non-methane hydrocarbons (NMHCs), total hydrocarbons (THCs), and methane $\left(\mathrm{CH}_{4}\right)$ ) during the cold season using a generalization of multifractal detrended crosscorrelation analysis (MF-DCCA). The results showed that the cross-correlations for different pairs of ozone precursors had multifractal characteristics and the generalized Hurst exponents for different pairs differed.
The MF-DCCA is a powerful method that can be used to investigate the cross-correlations between two time series. However, it cannot be used to investigate simultaneously the coupled correlations of several time series simultaneously. For example, the MF-DCCA can be used to analyze the cross-correlation of all air pollutant time series with $\mathrm{PM}_{2.5}$ and $\mathrm{PM}_{10}$. However, it cannot investigate the coupled correlations of nine air pollution time series such as fine particulate matter $\left(\mathrm{PM}_{2.5}\right)$, inhalable particulate matter $\left(\mathrm{PM}_{10}\right)$, sulfur dioxide $\left(\mathrm{SO}_{2}\right)$, nitrogen dioxide $\left(\mathrm{NO}_{2}\right)$, ozone $\left(\mathrm{O}_{3}\right)$, carbon monoxide $(\mathrm{CO})$, nitric oxide $(\mathrm{NO})$, nitrogen oxide (NOx), and ammonia $\left(\mathrm{NH}_{3}\right)$ at the same time [63]. The coupling detrended fluctuation analysis (CDFA) is an extended MF-DXA that is used to investigate the coupled correlations of several time series simultaneously [45].

In this study, we used this method to explore what is the role of a given air pollutant in the air pollution in four cities. After the shuffling procedure and phase-randomization, we found that carbon monoxide $(\mathrm{CO})$, nitrogen dioxide $\left(\mathrm{NO}_{2}\right)$, inhalable particulate matter $\left(\mathrm{PM}_{10}\right)$, and sulfur dioxide $\left(\mathrm{SO}_{2}\right)$ were important air pollutants in affecting air quality, whereas fine particulate matter $\left(\mathrm{PM}_{2.5}\right)$ and ozone $\left(\mathrm{O}_{3}\right)$ were less important. Our findings are different from those reported by Hedayatifar et al. [45]. Using the shuffling procedure, they found that ozone $\left(\mathrm{O}_{3}\right)$ played an important role in affecting air quality, whereas nitrogen dioxide $\left(\mathrm{NO}_{2}\right)$ was less important. The importance of nitrogen dioxide $\left(\mathrm{NO}_{2}\right)$ in affecting air quality increases when the original series is phase-randomized.

\section{Conclusions}

In this study, we used the backward trajectory model and multifractal methods to analyze the air pollution in Zhengzhou. The HYSPLIT model was used to divide the trajectories of air masses into five groups: Cluster 1, Cluster 2, Cluster 3, Cluster 4, and Cluster 5. Most clusters in each month originated from southern Hebei, eastern Shandong, and mid-western Henan and were then transported to Zhengzhou. We further adopted the PSCF and CWT models to identify potential source regions. The results are consistent with the HYSPLIT analysis. Four representative cities were selected to explore how close the air pollution of Zhengzhou is to other areas on the basis of air polluted concentration.

We used the MF-DFA method to explore if the air polluted time series in Zhengzhou had multifractal characteristics. Log-log plots of fluctuation functions, generalized Hurst exponent, Renyi exponent, and singularity spectrum all provided evidence of the multifractality of the AQI time series in Zhengzhou. Hence, we found that the multifractal method was feasible for our purpose. We then used the MF-DCCA method to investigate how close the AQI series of Zhengzhou is to that of each of other four cities. All of the cross-correlation exponents $h_{x y}(q)$ decreased with $q$ varying from -10 to 10 , which implied that the AQI series of Zhengzhou and those of the other four cities had multifractal nature. The widths of the multifractal spectra showed that the air pollution in Zhengzhou was 
closest to that in Jinan, followed by Shijiazhuang, Zibo, and Luoyang. Finally, we used the CDFA method to further explore what is the role of the given air pollutants, $\mathrm{PM}_{2.5}, \mathrm{PM}_{10}, \mathrm{SO}_{2}, \mathrm{NO}_{2}, \mathrm{O}_{3}$, and $\mathrm{CO}$, in the air pollution of the four cities. The results showed that carbon monoxide (CO) had the strongest impact on the air pollution, while sulfur dioxide $\left(\mathrm{SO}_{2}\right)$ had the least impact on the air pollution in Shijiazhuang and Jinan. Nitrogen dioxide $\left(\mathrm{NO}_{2}\right)$ was important to the air pollution in Jinan but less so in Shijiazhuang. As for Zibo, inhalable particulate matter $\left(\mathrm{PM}_{10}\right)$ had the strongest impact on the air pollution, while ozone $\left(\mathrm{O}_{3}\right)$ had the weakest impact on the air pollution. $\mathrm{SO}_{2}$ affected the air pollution in Luoyang the most.

The findings of this research provide useful references for air pollution sources and their potential contributions in Zhengzhou. Each city should take measures to control industrial enterprises' pollution emissions, to manage motor vehicle pollution emissions, and to establish no-coal-fired areas and basically no-coal-fired areas. Enterprises should improve their technological level, reform the production process to realize ecological benefits, and optimize their energy structure. Importantly, air pollution control and management is not one city's independent responsibility; instead, many cities must coordinate to achieve this goal. Hence, cities should collaborate to improve the ecological environment and achieve sustainable development.

\section{Data Availability}

The data used to support the findings of this study are available from the corresponding author upon request.

\section{Conflicts of Interest}

The authors declare that they have no conflicts of interest.

\section{Acknowledgments}

This study was funded by the National Social Science Foundation of China (Study on Financial Flexibility, Internal Control Quality and Enterprise Value) (grant no. 18BGL069).

\section{References}

[1] J. M. Prospero, F.-X. Collard, J. Molinié, and A Jeannot, "Characterizing the annual cycle of African dust transport to the Caribbean Basin and South America and its impact on the environment and air quality," Global Biogeochemical Cycles, vol. 7, pp. 757-773, 2014.

[2] Z. Q. Li, J. P. Guo, and A. J. Ding, "Aerosol and boundarylayer interactions and impact on air quality," National Science Review, vol. 6, pp. 810-833, 2017.

[3] Z. Q. Li, Y. Wang, and J. P. Guo, "East Asian study of tropospheric aerosols and their impact on regional clouds, recipitation, and climate (EAST-AIRCPC)," Journal of Geophysical Research: tmospheres, vol. 23, pp. 13026-13054, 2019.

[4] P. Bogawski, K. Borycka, and $Ł$ Grewling, "Detecting distant sources of airborne pollen for Poland: Integrating back-trajectory and dispersion modelling with a satellite-based phenology," Science of the Total Environment, vol. 689, pp. 109-125, 2019.

[5] M. F. Yassin, S. K. Almutairi, and A. Al-Hemoud, "Dust storms backward Trajectories' and source identification over Kuwait,” Atmospheric research, vol. 212, pp. 158-171, 2018.

[6] M. A. Bari and W. B. Kindzierski, "Characteristics of air quality and sources affecting fine particulate matter $\left(\mathrm{PM}_{2.5}\right)$ levels in the City of Red Deer," Canada. Environmental Pollution, vol. 221, pp. 367-376, 2017.

[7] M. C. Chalbot, B. McElroy, and I. G. Kavouras, "Sources, trends and regional impacts of fine particulate matter in southern Mississippi valley: Significance of emissions from sources in the Gulf of Mexico coast," Atmospheric Chemistry and Physics, vol. 7, pp. 3721-3732, 2013.

[8] R. Saini, A. Taneja, and P. Singh, "Surface ozone scenario and air quality in the north-central part of India," Journal of Environmental Sciences, vol. 59, pp. 72-79, 2017.

[9] Y. I. Tsai, K. Sopajaree, and S. C. Kuo, "Potential PM2. 5 impacts of festival-related burning and other inputs on air quality in an urban area of southern Taiwan," Science of the Total Environment, vol. 527, pp. 65-79, 2015.

[10] S. Wang, C. Li, and H. Zhou, "Impact of China's economic growth and energy consumption structure on atmospheric pollutants: Based on a panel threshold model," Journal of Cleaner Production, vol. 236, p. 117694, 2019.

[11] B. Brunekreef and B. Forsberg, "Epidemiological evidence of effects of coarse airborne particles on health," European Respiratory Journal, vol. 2, pp. 309-318, 2005.

[12] M. L. Croze, L. Zimmer, and H. G. Lee, "Ozone atmospheric pollution and Alzheimer's disease: from epidemiological facts to molecular mechanisms," Journal of Alzheimers Disease, vol. 2, pp. 503-522, 2018.

[13] J. Wang, W. Shao, and J. Kim, "Multifractal detrended crosscorrelation analysis between respiratory diseases and haze in South Korea," Chaos Solitons \& Fractals, vol. 135, pp. 1-10, 2020.

[14] F. Everson, D. S. Martens, and T. S. Nawrot, "Personal exposure to $\mathrm{NO}_{2}$ and benzene in the Cape Town region of South Africa is associated with shorter leukocyte telomere length in women," Environmental Research, vol. 182, Article ID 108993 , 2020.

[15] D. Granieri, F. Vita, and S. Inguaggiato, "Volcanogenic $\mathrm{SO}_{2}$, a natural pollutant: measurements, modeling and hazard assessment at vulcano Island (Aeolian Archipelago, Italy)," Environmental pollution, vol. 231, pp. 219-228, 2017.

[16] E. Conticini, B. Frediani, and D. Caro, "Can atmospheric pollution be considered a co-factor in extremely high level of SARS-COV-2 lethality in Northern Italy?" Environmental pollution, vol. 261, Article ID 114465, 2020.

[17] Y. Yao, J. Pan, and W. Wang, "Association of particulate matter pollution and case fatality rate of COVID-19 in 49 Chinese cities," Science of the Total Environment, vol. 741, Article ID 140396, 2020.

[18] J. Li, H. Yang, and S. Zha, "Effects of COVID-19 emergency response levels on air quality in the Guangdong-Hong KongMacao greater bay area, China," Aerosol and Air Quality Research, vol. 2, Article ID 2000146, 2021.

[19] T. Xian, Z. Li, and J. Wei, "Changes in air pollution following the COVID-19 Epidemic in Northern China: the role of meteorology," Frontiers in Environmental Science, vol. 9, Article ID 654651, 2021.

[20] I. D. Sulaymon, Y. Zhang, and P. K. Hopke, "COVID-19 pandemic in Wuhan: Ambient air quality and the relationships between criteria air pollutants and meteorological 
variables before, during, and after lockdown," Atmospheric Research, vol. 250, Article ID 105362, 2021.

[21] M. Filonchyk and M. Peterson, "Air quality changes in Shanghai, China, and the surrounding urban agglomeration during the COVID-19 lockdown," Journal of Geovisualization and Spatial Analysis, vol. 2, pp. 1-7, 2020.

[22] Y. Huang, Q. Yan, and C. Zhang, "Spatial-temporal distribution characteristics of $\mathrm{PM}_{2.5}$ in China in 2016," Journal of Geovisualization and Spatial Analysis, vol. 2, pp. 1-18, 2018.

[23] F. Karaca and F. Camci, "Distant source contributions to $\mathrm{PM}_{10}$ profile evaluated by SOM based cluster analysis of air mass trajectory sets," Atmospheric Environment, vol. 7, pp. 892-899, 2010.

[24] F. Ngan and D. Byun, "Classification of weather patterns and associated trajectories of high-ozone episodes in the Houston-Galveston-Brazoria area during the 2005/06 TexAQS-II," Journal of applied meteorology and climatology, vol. 3, pp. 485-499, 2011.

[25] I. S. Kim, J. Y. Lee, and Y. P. Kim, "Impact of polycyclic aromatic hydrocarbon (PAH) emissions from North Korea to the air quality in the Seoul Metropolitan Area, South Korea," Atmospheric Environment, vol. 70, pp. 159-165, 2013.

[26] K. Dimitriou and P. Kassomenos, "The covariance of air quality conditions in six cities in Southern Germany-The role of meteorology," Science of the Total Environment, vol. 574, pp. 1611-1621, 2017.

[27] M. C. G. Chalbot, I. Nicolis, and C. Guihenneuc-Jouyaux, "Multiyear analyses of ground-level air contaminants over Paris metropolitan region using real-time observations and air mass backward trajectories," Particuology, vol. 28, pp. 60-71, 2016.

[28] T. Sun, H. Che, and B. Qi, "Aerosol optical characteristics and their vertical distributions under enhanced haze pollution events: effect of the regional transport of different aerosol types over eastern China," Atmospheric Chemistry and Physics, vol. 4, pp. 2949-2971, 2018.

[29] D. G. Kaskaoutis, U. C. Dumka, and A. Rashki, "Analysis of intense dust storms over the eastern Mediterranean in March 2018: impact on radiative forcing and athens air quality," Atmospheric environment, vol. 209, pp. 23-39, 2019.

[30] H. Yu, J. Feng, and X. Su, "A seriously air pollution area affected by anthropogenic in the central China: tempora1-spatial distribution and potential sources," Environmental geochemistry and health, vol. 10, pp. 3199-3211, 2020.

[31] M. Filonchyk and H. Yan, "The characteristics of air pollutants during different seasons in the urban area of Lanzhou, Northwest China," Environmental Earth Sciences, vol. 22, pp. 1-17, 2018.

[32] L. Li, D. Yan, and S. Xu, "Characteristics and source distribution of air pollution in winter in Qingdao, eastern China," Environmental Pollution, vol. 224, pp. 44-53, 2017.

[33] Q. Hong, C. Liu, and Q. Hu, "Evolution of the vertical structure of air pollutants during winter heavy pollution episodes: the role of regional transport and potential sources," Atmospheric Research, vol. 228, pp. 206-222, 2019.

[34] G. M. Pereira, N. D. O. Alves, and S. E. S. Caumo, "Chemical composition of aerosol in São Paulo, Brazil: influence of the transport of pollutants. air quality," Atmosphere \& Health, vol. 4, pp. 457-468, 2017.

[35] J. Sentian, F. Herman, and C. Y. Yih, "Long-term air pollution trend analysis in Malaysia," International Journal of Environmental Impacts, vol. 4, pp. 309-324, 2019.

[36] P. Punsompong and S. Chantara, "Identification of potential sources of $\mathrm{PM}_{10}$ pollution from biomass burning in northern
Thailand using statistical analysis of trajectories," Atmospheric Pollution Research, vol. 6, pp. 1038-1051, 2018.

[37] R. Dejchanchaiwong, P. Tekasakul, and S. Tekasakul, "Impact of transport of fine and ultrafine particles from open biomass burning on air quality during 2019 Bangkok haze episode," Journal of Environmental Sciences, vol. 97, pp. 149-161, 2020.

[38] Y. Taniguchi, K. Shimada, and A. Takami, "Transboundary and local air pollutants in western Japan distinguished on the basis of ratios of metallic elements in size-segregated aerosols," Aerosol and Air Quality Research, vol. 12, pp. 3141-3150, 2017.

[39] T. Mukherjee, A. Asutosh, and S. K. Pandey, "Increasing potential for air pollution over megacity New Delhi: a study based on 2016 diwali episode," Aerosol and Air Quality Research, vol. 9, pp. 2510-2518, 2018.

[40] J. W. Kantelhardt, S. A. Zschiegner, and E. Koscielny-Bunde, "Multifractal detrended fluctuation analysis of nonstationary time series," Physica A Statal Mechanics \& Its Applications, vol. 316, pp. 87-114, 2002.

[41] W. Mensi, A. K. Tiwari, and S. M. Yoon, "Global financial crisis and weak-form efficiency of Islamic sectoral stock markets: An MF-DFA analysis," Physica A: Statistical Mechanics and its Applications, vol. 471, pp. 135-146, 2017.

[42] S. J. H. Shahzad, S. M. Nor, and W. Mensi, "Examining the efficiency and interdependence of US credit and stock markets through MF-DFA and MF-DXA approaches," Physica A: Statistical Mechanics and its Applications, vol. 471, pp. 351363, 2017.

[43] W. X. Zhou, "Multifractal detrended cross-correlation analysis for two nonstationary signals," Physical Review E Statal Nonlinear \& Soft Matter Physics, vol. 6, Article ID 066211, 2008.

[44] L. Yang, Y. Zhu, and Y. Wang, "Multifractal detrended crosscorrelations between crude oil market and Chinese ten sector stock markets," Physica A: Statistical Mechanics and Its Applications, vol. 462, pp. 255-265, 2016.

[45] L. Hedayatifar, M. Vahabi, and G. R. Jafari, "Coupling detrended fluctuation analysis for analyzing coupled nonstationary signals," Physical Review E, vol. 2, Article ID 021138, 2011

[46] C. K. Lee, L. C. Juang, and C. C. Wang, "Scaling characteristics in ozone concentration time series (OCTS)," Chemosphere, vol. 6, pp. 934-946, 2006.

[47] Y. Xue, W. Pan, and W. Z. Lu, "Multifractal nature of particulate matters (PMs) in Hong Kong urban air," Science of The Total Environment, vol. 532, pp. 744-751, 2015.

[48] Z. Liu, L. Wang, and H. Zhu, "A time-scaling property of air pollution indices: a case study of Shanghai, China," Atmospheric Pollution Research, vol. 5, pp. 886-892, 2015.

[49] C. Shen, Y. Huang, and Y. Yan, "An analysis of multifractal characteristics of API time series in Nanjing, China," Physica A: Statistical Mechanics and its Applications, vol. 451, pp. 171-179, 2016.

[50] Q. Dong, Y. Wang, and P. Li, "Multifractal behavior of an air pollutant time series and the relevance to the predictability," Environmental Pollution, vol. 222, pp. 444-457, 2017.

[51] C. Zhang, Z. Ni, and L. Ni, "Multifractal detrended crosscorrelation analysis between $\mathrm{PM}_{2.5}$ and meteorological factors," Physica A: Statistical Mechanics and its Applications, vol. 438, pp. 114-123, 2015.

[52] C. Stan, L. Marmureanu, and C. Marin, "Investigation of multifractal cross-correlation surfaces of Hurst exponents for some atmospheric pollutants," Physica A: Statistical Mechanics and its Applications, vol. 545, Article ID 123799, 2020. 
[53] X. Kong, W. He, and N. Qin, "Comparison of transport pathways and potential sources of $\mathrm{PM}_{10}$ in two cities around a large Chinese lake using the modified trajectory analysis," Atmospheric research, vol. 122, pp. 284-297, 2013.

[54] S. Wang, S. Yu, and R. Yan, "Characteristics and origins of air pollutants in Wuhan, China, based on observations and hybrid receptor models," Journal of the Air \& Waste Management Association, vol. 7, pp. 739-753, 2017.

[55] Y. L. Dong, X. Jiang, and Z. H. Liang, "Coal power flexibility, energy efficiency and pollutant emissions implications in China: a plant-level analysis based on case units," Resources, Conservation and Recycling, vol. 134, pp. 184-195, 2018.

[56] H. Zhang, B. Zhang, and J. Bi, "More efforts, more benefits: Air pollutant control of coal-fired power plants in China," Energy, vol. 80, pp. 1-9, 2015.

[57] G. B. Bi, Y. Y. Shao, and W. Song, "A performance evaluation of China's coal-fired power generation with pollutant mitigation options," Journal of Cleaner Production, vol. 171, pp. 867-876, 2018.

[58] B. Podobnik, I. Grosse, and D. Horvatić, "Quantifying crosscorrelations using local and global detrending approaches," The European Physical Journal B, vol. 2, pp. 243-250, 2009.

[59] X. Chen, S. Yu, and L. Wang, "Common source areas of air pollution vary with haze intensity in the Yangtze River Delta, China," Environmental Chemistry Letters, vol. 6, pp. 1-9, 2020.

[60] D. D. Genc, C. Yesilyurt, and G. Tuncel, "Air pollution forecasting in Ankara, Turkey using air pollution index and its relation to assimilative capacity of the atmosphere," Environmental monitoring and assessment, vol. 166, pp. 11-27, 2010.

[61] C. Varotsos, J. Ondov, and M. Efstathiou, "Scaling properties of air pollution in Athens, Greece and Baltimore, Maryland," Atmospheric Environment, vol. 22, pp. 4041-4047, 2005.

[62] A. M. Diosdado, G. G. Coyt, and J. A. B. López, "Multifractal analysis of air pollutants time series," Revista Mexicana de Física, vol. 1, pp. 7-13, 2013.

[63] P. Manimaran and A. C. Narayana, "Multifractal detrended cross-correlation analysis on air pollutants of University of Hyderabad Campus, India," Physica A: Statistical Mechanics and Its Applications, vol. 502, pp. 228-235, 2018. 